NBER WORKING PAPER SERIES

THE ELECTRIC GINI:
INCOME REDISTRIBUTION THROUGH ENERGY PRICES

Arik Levinson

Emilson Silva

Working Paper 26385

http://www.nber.org/papers/w26385

NATIONAL BUREAU OF ECONOMIC RESEARCH

1050 Massachusetts Avenue

Cambridge, MA 02138

October 2019

The authors are grateful to the Georgetown Environmental Initiative for financial assistance; and to Kevin Ankney, Becka Brolinson, Grady Killeen, JJ Nadeo, and Mark Noll for research assistance; and to many who commented on early drafts, including Sarah Aldy, Sylwia Bialek, Severin Borenstein, Timothy Fitzgerald, Matt Freedman, Rong Hai, Nick Muller, David Rapson, and Joseph Shapiro. The views expressed herein are those of the authors and do not necessarily reflect the views of the National Bureau of Economic Research.,

NBER working papers are circulated for discussion and comment purposes. They have not been peer-reviewed or been subject to the review by the NBER Board of Directors that accompanies official NBER publications.

(C) 2019 by Arik Levinson and Emilson Silva. All rights reserved. Short sections of text, not to exceed two paragraphs, may be quoted without explicit permission provided that full credit, including $(\odot$ notice, is given to the source. 
The Electric Gini: Income Redistribution through Energy Prices

Arik Levinson and Emilson Silva

NBER Working Paper No. 26385

October 2019

JEL No. Q41,Q48

\begin{abstract}
$\underline{\text { ABSTRACT }}$
Efficient electricity pricing involves two-part tariffs: a volumetric price equal to the marginal cost of producing an additional kilowatt hour $(\mathrm{kWh})$ and a fixed fee to cover any remaining fixed costs. In this paper we explore how US electricity regulators depart from this simple two-part tariff to address concerns about income inequality. We first show that in theory, price setters concerned about inequality will charge lower fixed monthly fees and higher per-kWh prices, and increasing block prices to target higher users with even higher prices. Then we use a new dataset of 1,300 utilities across the US to show that these theoretical predictions are borne out in practice. Utilities whose ratepayers have more unequal incomes levy more redistributive tariffs, charging less to low users and more to high users. To quantify these comparisons, we develop a new measure of the redistributive extent of utility tariffs that we call the "electric Gini." Utilities with higher electric Ginis (more redistributive tariffs) shift costs from households that use relatively little electricity to households that use more. But because electricity use is only loosely correlated with income, that redistribution does not meaningfully shift costs from households with low incomes to those with high incomes.
\end{abstract}

Arik Levinson

Department of Economics ICC 571

Georgetown University

3700 O St., NW

Washington, DC 20057

and NBER

Arik.Levinson@georgetown.edu

Emilson Silva

Alberta School of Business 3-40L-1

University of Alberta

Edmonton, Alberta

Canada

emilson@ualberta.ca 


\section{The Electric Gini: Income Redistribution through Energy Prices}

Electricity is a textbook high-fixed-cost, low-marginal-cost industry. Power plants and transmission lines cost billions of dollars to build, regardless of how many kilowatt-hours (kWh) are generated and transmitted. Once built, producing an extra kWh of energy costs only a few pennies. Consequently, an efficient way for utilities to price their electricity is to use a two-part tariff (Bonbright, 1988). A per-kWh volumetric charge covers the marginal cost of producing an extra kWh of electricity. And a fixed monthly access charge assessed to each household, regardless of how many kWh they use, covers any remaining fixed costs of building and operating the power plant and transmission lines.

In practice, residential prices in the US are set by politically appointed or elected regulators and differ from this simple two-part tariff in two important ways. First, in most places in the US the volumetric price per kWh exceeds the marginal cost of producing electricity. That is often true even if we include external social costs of pollution. ${ }^{1}$ Utilities charge inefficiently high per-kWh prices.

The second departure from efficient prices is newer. In more and more places, electric utilities charge increasing block prices, in which the price per kWh increases step-wise with consumption. ${ }^{2}$ These tiered prices are plainly inefficient - different customers pay different marginal per-kWh prices, even though the electricity costs the same to produce.

Why do regulators approve non-marginal volumetric prices? One stated reason is to protect low-income households who use less electricity (Borenstein 2012, 2016). Low users, with presumably lower incomes, pay low access fees and low per-kWh rates. High users face the higher rates associated with upper tiers of increasing block prices. The websites and mission statements of some utilities and their regulators publicize this objective explicitly. California's Public Utilities Commission seeks to ensure that rates are "just," New York's Department of Public Service aims for rates that are "affordable," and the regulators in Ohio and Wisconsin

\footnotetext{
${ }^{1}$ Borenstein and Bushnell (2018).

${ }^{2}$ Utilities around the world are adopting these types of increasing block prices. See World Bank (2017) and Zhang et al. (2017).
} 
both claim to strive for rates that are "fair." Utilities - or their regulators — trade off efficiency for distributional objectives. ${ }^{3}$

We ask two questions here. First, do utilities that serve customers with more unequal incomes have price structures that do more to protect low-income households? And second, how much redistribution takes place via electricity prices?

We begin by framing the questions with some simple theory. Absent redistributive goals, a two-part tariff is efficient, as has been recognized since at least Hotelling (1938), Coase (1946), and Feldstein (1972). A utility regulator with a homogenous customer base, in which all ratepayers have equal incomes, would have no reason to depart from that efficient two-part tariff. Per-kWh prices can match marginal costs, and fixed monthly access fees can be high enough to cover the remaining fixed costs. But if a utility's ratepayers have unequal incomes, a regulator might want to favor low-income ratepayers who presumably use less electricity. A regulator who can set individualized tariffs will want to set uniform per-kWh prices equal to marginal costs and monthly access fees that vary with household income. If individualized fixed monthly fees are infeasible, the regulator can favor low-income ratepayers by charging individualized per-kWh prices or by setting prices based on electricity use, as with increasing block prices, charging lower-than efficient prices to low users and higher-than-efficient prices to high users.

To see whether electricity tariffs reflect these distributional goals, we assemble a new dataset of electricity pricing schedules, or tariffs, for more than 1,300 electric utilities across the United States. We use that dataset to construct a new measure of the redistributional nature of the utilities" tariffs - the "electric Gini" of our title. We then match those tariffs and electric Ginis to US Census data on the income inequality of their ratepayers, as measured by more familiar, standard income Gini coefficients. Those income Gini coefficients are correlated with electric Ginis, even after controlling for other utility and ratepayer characteristics. Utilities serving ratepayers with less equal incomes have price schedules with more redistribution, evidence that electricity pricing has a redistributive goal.

\footnotetext{
${ }^{3}$ Note that this discussion ignores dynamic time-of-day or congestion pricing, for two reasons. First, few utilities in the US charge such real-time prices. Until recently, the necessary smart-meter technology was not available, and customers currently appear resistant to its implementation. Second, and more importantly, residential electricity customers appear to ignore marginal prices anyway, focusing only on their total monthly bills (Ito, 2014). So even if utilities charged dynamic prices, the primary economic consequence would involve equity, not efficiency.
} 
Our second question asks how much redistribution takes place via electricity pricing. That question necessarily has two parts. By how much does the rate structure redistribute costs from low users of electricity to high users? And how much does that redistribution among users redistribute costs across incomes? Those parts can have different answers because electricity use and incomes are not perfectly correlated. Electricity use is an indirect tool for addressing income inequality.

Utilities that serve households with income Gini coefficients 0.1 points higher (on a 0-to1 scale) have electric Ginis that are 0.007 to .015 points higher during the summer. That makes the redistribution sound significant, offsetting 7 to 15 percent of income inequality differences. But because income is not very well correlated with electricity consumption, those higher electric Ginis have little effect on underlying income inequality.

To assess the effect of electricity tariffs on inequality, we subtract monthly electric bills from a representative distribution of households' incomes, generating "net-of-electricity" incomes. In utilities with high electric Ginis, that shrinks the net-of-electricity income inequality. In utilities with low electric Ginis, those utility bills enlarge the net-of-electricity inequality. The difference in net-of-electricity income Ginis between the most and least redistributive utility is large: about 0.31 on the 0 -to- 1 Gini scale. But most of that comes from differences between utilities in the cost of their electricity, not how those costs are distributed among customers. In Hawaii, where electricity is expensive, nearly any bill structure will be regressive because electricity bills are large relative to incomes. If we just focus on places where electricity costs are similar, and the average US household would pay about \$108 per month, the largest difference in net-of-electricity Ginis is only 0.008. By contrast, household income Ginis differ across regions of the US by 0.13 , making the income redistribution via electricity prices seem small.

Pieces of this analysis have been addressed in prior work. Borenstein and Davis (2017) show that natural gas use in the US is weakly correlated with incomes, and so charging higherthan-efficient marginal prices is "only mildly progressive." Borenstein (2012) poses similar questions for electricity use in California and finds only "modest" redistribution from current increasing-block tariffs. Burger et al. (2019) invert the question, and ask how much more or less each income group would pay if Chicago-area electricity ratepayers were charged efficient tariffs. And Feger and Radulescu (2018) show that in one large Swiss city, electricity prices are marked up above marginal costs, in a way that implies conservation goals dominate 
distributional concerns. Our analysis covers all of the United States, describes the degree to which utilities serving more unequal ratepayers charge more redistributive electricity tariffs, and measures how much redistribution those tariffs accomplish.

Our work thus has three conclusions. First, in theory, regulators concerned about income inequality can set electricity prices to meet distributional goals. Section I describes that theoretical result. Second, in practice regulators in the US seem to do just that - design electricity tariffs with distributional objectives. But third, because income and electricity use are only weakly correlated, the resulting redistribution of costs from low users of electricity to high users has little effect on underlying income inequities. Section II describes those empirical findings.

\section{Theory: Efficiency versus Equity}

Start with a general, admittedly simplistic model, in which one regulated utility serves $n$ identical households. Each representative household $i$ has welfare from electricity $\left(e^{i}\right)$ and a numeraire good $\left(x^{i}\right)$ :

$$
u\left(e^{i}, x^{i}\right)
$$

Each identical household has income $w$ and a budget constraint

$$
w=x^{i}+p e^{i}+t
$$

where $p$ is the price per kWh of electricity and $t$ is the fixed monthly access fee. Each household maximizes (1) subject to (2) leading to first-order conditions

$$
u_{e}^{i} / u_{x}^{i}=p \quad i=1, \ldots, n
$$

and equation (2), where $u_{x} \equiv \partial u(e, x) / \partial x$ and $u_{e} \equiv \partial u(e, x) / \partial e$.

Prices $p$ and $t$ are chosen by a utility regulator who maximizes the sum of household welfare: ${ }^{4}$

$$
\sum_{i} u\left(e^{i}, w-t-p e^{i}\right)
$$

\footnotetext{
${ }^{4}$ In what passes for an economic double entendre, the regulator here is "utilitarian."
} 
(substituting the household's budget constraint in for $x^{i}$ ). That regulator has to ensure that the electricity producer breaks even, which means that revenues equal costs, or

$$
p \sum_{i} e^{i}+n t=c \sum_{i} e^{i}+F
$$

where $c$ is the marginal cost of producing electricity, and $F$ is the fixed cost. Maximizing (4) subject to (5) leads to first-order conditions

$$
u_{e}^{i}-p u_{x}^{i}+\lambda(p-c)=0 \quad i=1, \ldots, n,
$$

where $\lambda$ is the Lagrange multiplier associated with constraint (5). Substituting in (3) leads to the result that

$$
c=p \text { and } t=F / n \text {. }
$$

The regulator should charge each identical household $c$ for every kWh of electricity used and $t=F / n$ for a proportional share of the fixed cost. For efficiency, the households should pay a price per $\mathrm{kWh}$ equal to the marginal production cost, $c$. The fixed cost $F$ can then be covered by the fixed monthly access fee $t$.

Economists have recognized this simple result since at least Hotelling (1938) and Coase (1946). But here we are interested in the distributional concerns when households differ.

\section{A. Heterogeneous households and distributional concerns}

Now consider households with different incomes, $w^{i}, i=1, \ldots, n$. Begin by assuming the regulator can charge each household a different price $p^{i}$ and a different access fee $t^{i}$. This allows us to characterize the first best, efficient, welfare-maximizing tariff. Later we analyze more realistic cases where the regulator cannot charge personalized access fees or prices. Define each household's net income $\hat{w}^{i}$ as its income minus the fixed part of its monthly electricity bill, $t^{i}$. Then each household's budget constraint is $x^{i}+p^{i} e^{i}=\hat{w}^{i} \equiv w^{i}-t^{i}$.

Each household $i$ takes its individual access fee $\left(t^{i}\right)$ and price $\left(p^{i}\right)$ as given, and chooses the amount of electricity $\left(e^{i}\right)$ to maximize $u\left(e^{i}, \hat{w}^{i}-p^{i} e^{i}\right)$. A welfare-maximizing electricity 
regulator chooses prices $\left\{p^{1}, \ldots, p^{n}, t^{1}, \ldots, t^{n}\right\}$ to maximize the sum of the indirect utilities of its customers $\sum_{i=1}^{n} v\left(p^{i}, w^{i}-t^{i}\right)$, subject to the constraint that revenues cover costs:

$$
\sum_{i=1}^{n}\left[t^{i}+\left(p^{i}-c\right) e^{i}\left(p^{i}, w^{i}-t^{i}\right)\right]=F
$$

Using the first-order condition from this welfare maximization problem, Roy's identity, and the Slutsky equation, we can then show that in the optimum, for all $i, j=1, \ldots, n, i \neq j$,

$$
\begin{gathered}
p^{i}=p^{j}=c \text {, and } \\
\hat{w}^{i} \equiv w^{i}-t^{i}=w^{j}-t^{j} \equiv \hat{w}^{j} .
\end{gathered}
$$

The regulator should charge each person the same, constant, per-kWh electricity price equal to the marginal production cost, $c$, and an individualized access fee, $t^{i}$, so that each person's budget net of that access fee, $\hat{w}^{i}$, is equal. (See Appendix A for a proof.)

Equations (9) and (10) are intuitive. Given the option of individual prices and access fees, the welfare-maximizing regulator would choose uniform prices but individualized access fees. With a utilitarian goal of maximizing total welfare, the regulator should price electricity efficiently so that $p^{i}=c$ for everybody and redistribute income via the fixed access fees $t^{i}$ to maximize welfare. In this simple case, where people differ only by their incomes, maximizing utility means equalizing incomes.

This setup —individualized electricity tariffs - is obviously unrealistic. The fixed access fees, $t^{i}$, act as lump-sum taxes and transfers that redistribute income. Given declining marginal utility and a utilitarian objective, the regulator here uses the access fees to completely equalize incomes. That is not only politically unlikely, but it is also technically impractical given that incomes differ by far more than electricity bills. Such a scheme would require confiscatory access fees for some high-income ratepayers and large access subsidies for low-income ones. As a step toward more realism, next we consider instead uniform monthly access fees, $t$, but individualized prices, $p^{i}$. 


\section{B. Constrained optimum: Uniform access fees $(t)$ and individualized prices $\left(p^{i}\right)$}

Consider now the same problem as above, but with an additional constraint that the regulator cannot set individualized access fees: $t^{i}=t$ for all $i$. The regulator's problem becomes the choice of $\left\{p^{i}, \ldots, p^{n}, t\right\}$ to maximize welfare $\sum_{i} v\left(p^{i}, w^{i}-t\right)$ subject to the utility's break-even condition:

$$
n t+\sum_{i}\left(p^{i}-c\right) e^{i}\left(p^{i}, w^{i}-t\right)=F .
$$

In Appendix B we show that the solution to this problem implies that

$$
L^{j} \equiv \frac{p^{j}-c}{p^{j}}=\frac{-1}{\varepsilon_{p}^{j}}\left[1-\left(\frac{v_{\hat{w}}^{j}}{\sum_{i} v_{\hat{w}}^{i}}\right)\left(n-\sum_{i}\left(p^{i}-c\right) e_{\hat{w}}^{i}\right)\right], \quad \forall j
$$

where $L^{j}$ is a version of the Lerner index of monopoly power with respect to household $j$, and $\varepsilon_{p}^{j}$ is household $j$ 's price elasticity of electricity demand: $\left(\partial e^{j} / \partial p^{j}\right)(p / e)<0$.

The left-hand side of (12) is just the markup (or mark-down) of prices relative to the marginal cost of electricity. On the right-hand side, the first term, $-1 / \varepsilon_{p}^{j}$, is the standard Lerner index. The monopoly markup $\left(p^{j}-c\right)$ decreases with the demand elasticity of the monopolized $\operatorname{good}\left(\varepsilon_{p}^{j}\right)$. In this case, the regulator cares about distributional effects, so equation (12) adjusts for each household's share of the total marginal utility of income (the $v_{\hat{w}}^{j}$ term) times the marginal revenue associated with incrementally raising the fixed access fee, the fraction inside the right-most bracketed term on the right side of (12). The whole term in square brackets in (12) can be positive or negative, so price $\left(p^{j}\right)$ can be higher or lower than marginal cost $(c)$. Since low-income customers have higher-than-average marginal utility of income, they pay prices that are lower than marginal cost, and high-income customers pay prices higher than marginal cost.

As we show empirically later, households' electricity demands differ for many reasons aside from income. That means that in practice varying electricity prices redistribute costs from low electricity users to high users - but not necessarily from low-income households to highincome ones. To model that distinction, we add endowments of electricity consumption to the model. 


\section{Solar panels and other sources of electricity demand heterogeneity aside from income}

Some high-income households do not use much electricity at their billing address. Consider two high-earning spouses working long days outside their home, or a wealthy family that travels often or has a weekend home, or a homeowner with solar panels on the roof. These high-income households will purchase less electricity from the grid — at any particular addressand contribute less to per-kWh revenues of the utility, $p^{i} e^{i}$. At the same time, some low-income households use a lot of electricity. Consider a large extended family, in a poorly insulated home, with inefficient window air conditioners or electric space heating.

To capture this non-income heterogeneity, we modify the model by assuming household $i$ is endowed with $\tilde{e}^{i}$ units of electricity. Think of a solar roof that generates $\tilde{e}^{i}$ per month, or a periodic vacation during which household demand declines by $\tilde{e}^{i}$. These electricity endowments are not necessarily related to household incomes.

Household $i$ 's budget constraint is then $x^{i}+p^{i}\left(e^{i}-\tilde{e}^{i}\right)=w^{i}-t$. Define $\tilde{w}^{i}$ as the household's exogenous income, including the value of its electricity endowment and net of access fees: $\tilde{w}^{i} \equiv w^{i}+p^{i} \tilde{e}^{i}-t$. Household $i^{\prime \prime}$ s net electricity demand is $e^{i}\left(p^{i}, \tilde{w}^{i}\right)$ and indirect utility is $v^{i}\left(p^{i}, \tilde{w}^{i}\right)$. The regulator chooses $\left\{p^{l}, \ldots, p^{n}, t\right\}$ to maximize $\sum_{i} v^{i}\left(p^{i}, \tilde{w}^{i}\right)$ subject to

$$
n t+\sum_{i}\left(p^{i}-c\right) e^{i}\left(p^{i}, \tilde{w}^{i}\right)=F .
$$

In Appendix $\mathrm{C}$ we show that the solution to this problem implies that

$$
\left.L^{j} \equiv \frac{p^{j}-c}{p^{j}}=\frac{-1}{\left(\varepsilon_{p}^{j}+\frac{\tilde{e}^{j}}{e^{j}} p^{j} e_{\tilde{w}}^{j}\right.}\right)\left[1-\left(\frac{v_{\tilde{w}}^{j}}{\sum_{i} v_{\tilde{w}}^{i}}\right)\left(\frac{e^{j}-\tilde{e}^{j}}{e^{j}}\right)\left(n-\sum_{i}\left(p^{i}-c\right) e_{\tilde{w}}^{i}\right)\right], \quad \forall j,
$$

where again $L^{j}$ is a version of the Lerner index of monopoly power and $\varepsilon_{p}^{j}$ is household $j$ 's price elasticity of electricity demand.

Equation (14) differs from (12) in two places. The new term in the denominator, $\frac{\tilde{e}^{j}}{e^{j}} p^{j} e_{\tilde{w}}^{j}$, is a function of the ratio of $j$ 's electricity endowment $\tilde{e}^{j}$ to its electricity demand $e^{j}$. We know from the Slutsky equation that the whole denominator is negative (see Appendix C), 
and if electricity is a normal good $\left(e_{\tilde{w}}^{j}>0\right)$, then the second term in that denominator is positive. So the larger is $\tilde{e}^{j}$ relative to $e^{j}$, the smaller in absolute value is the entire denominator, and the larger is the markup $p^{j}-c$. The regulator should mark up prices higher above costs for households with larger electricity endowments. People with solar panels or who are away from home more often should pay higher prices per $\mathrm{kWh}$, for reasons related to equity, not efficiency.

The second difference between equations (14) and (12) is the term $\left(\frac{e^{j}-\tilde{e}^{j}}{e^{j}}\right)$ inside the square brackets. That term is the share of the household's electricity purchased from the utility. The larger that share, the more likely is the entire right-hand side to be negative, and the more likely is the optimal price charged to $j$ to be higher than marginal cost. So two conditions lead to $p^{j}>c$ : first, if the household has low marginal utility of income, presumably because it has high income as was discussed for equation (12); and now, second, if the household is endowed with a higher share of its electricity consumption. ${ }^{5}$

In practice, most utilities do not charge prices that differ by household income, and instead charge prices that differ by usage, as with increasing block pricing. And even the few states that do have income-based electricity price subsidies - like California's CARE program, New York's Utility Assistance Program, and Lite-up Texas-also use increasing block pricing. Thus we next add that one final element of realism to the model.

\section{Increasing block pricing}

Consider a regulator that cannot charge prices based on income but can charge increasing block prices. To simplify as much as possible, we assume the access fee $t=0 .{ }^{6}$ Further simplifying, we assume that an exogenous rule determines the number of households facing each of two price tiers: $n_{L}$ low-using customers face price $p_{L}$ for each $\mathrm{kWh}$ of electricity up to threshold quantity $q$, and $n_{H}$ high-using customers face price $p_{H}$ for each $\mathrm{kWh}$ above $q$.

\footnotetext{
${ }^{5}$ Note that if the endowed electricity $\tilde{e}^{j}=0$, equation (14) collapses to equation (12).

${ }^{6}$ Some utilities do charge zero flat fees, instead applying a minimum monthly usage that is surpassed by most ratepayers.
} 
The regulator chooses the two prices and the threshold, $\left\{p_{L}, p_{H}, q\right\}$, to maximize the sum of the indirect utilities of the customers of both types, constrained such that total revenues equal total costs. In Appendix D we derive the resulting three first-order conditions with respect to $p_{L}$, $p_{H}$, and $q$. We show that they can be rearranged such that

$$
p_{L}<c<p_{H}
$$

and that the rate at which low-demand customers are subsidized with prices below marginal cost is proportional to the size of the gap between the high and low prices, and that the marginal social rate of substitution between the high and low electricity prices is proportional to the marginal social rate of transformation between high and low prices. In other words, the rate at which $p_{L}$ can be lowered and $p_{H}$ can be raised, while holding utility constant, is proportional to the rate at which those two prices can be altered while holding revenue constant.

The summary so far is straightforward. If the regulator can set individualized prices and access fees, the solution is prices equal to marginal cost $(p=c)$ and access fees that redistribute income to equalize marginal utility. If individualized access fees are not feasible, but individualized prices are, the solution is to charge high-income households prices above marginal cost, and low-income households prices below marginal cost. And if income-based prices are infeasible, the solution involves usage-based prices, like increasing block pricing, where high users pay higher prices for electricity consumed above some threshold.

The actual realizations of access fees and prices thus depend on the amount of redistribution desired, which in turn depends on two things: (1) the degree of income inequality among ratepayers, and (2) ratepayers' and voters' preferences about income inequality and the welfare of lower-income households. In Section II, we test both propositions, asking how much the redistributive nature of US electricity prices depends on the income inequality and political preferences of utilities' ratepayers.

\section{Empirics: Do Electricity Prices Respond to Income Inequality?}

To study the distributional causes and consequences of electricity pricing in the United States, we start with the US Utility Rate Database. ${ }^{7}$ Those data cover 2,500 different utilities,

\footnotetext{
${ }^{7}$ See http://en.openei.org/wiki/Utility Rate Database, accessed July 2019.
} 
with 7,600 different tariffs. We eliminate special tariffs, and we average across tariffs that apply to different jurisdictions within a utility's service area, such as those applying to different towns, or separate rates for rural and urban customers. ${ }^{8}$

For local population characteristics, including average household incomes and Gini coefficients of household income, we turn to the 2015 American Community Survey (ACS). Those data are organized by county. We combine them with county-level party vote shares, averaged across the 2000-to-2016 presidential elections. ${ }^{9}$

To match those county characteristics to particular utilities, we create a concordance based on zip codes. We know the zip codes served by each utility, so to merge those data with the county demographic information, we need two more things: (1) the zip codes corresponding to each county, and (2) the population of each zip code. We then construct a weighted average of the county characteristics, weighted by the combined populations of the zip codes served by each utility. ${ }^{10}$ The zip code-to-county crosswalk comes from the US Department of Housing and Urban Development. ${ }^{11}$ The number of households per zip code come from the US Census Bureau, via American Factfinder. ${ }^{12}$

Combining these sources yields a dataset of 1,305 tariffs, one for each utility, matched with local population demographics. Those utility-specific population characteristics-incomes, income inequality, and political vote shares — are the weighted average of the characteristics of the counties served by each utility, where the weights are the populations of the zip codes served by the utility in each county.

Table 1 describes those tariffs. Because many utilities have rate structures that vary by season, we call the August rates for each utility "summer" and the January rates "winter." A plurality of the utilities has fixed monthly fees and uniform flat rates per $\mathrm{kWh}$. But 514 have a second summer tier, more than 200 others have a third, and several dozens have more than that. We merge those price data with US Energy Information Administration (EIA) data that contain

\footnotetext{
${ }^{8}$ In particular, we ignore special tariffs that apply to water heaters, pumps, three-phase wiring systems, irrigation, public housing, or homes with electric cars or solar panels. We eliminate time-of-use tariffs and special tariffs for senior citizens and people with medical needs.

${ }^{9}$ From the MIT Election Lab https://electionlab.mit.edu/data, accessed August 2019.

${ }^{10}$ The zip codes served by each utility are at http://en.openei.org/.

${ }^{11}$ The crosswalk from zip codes to counties is at https://www.huduser.gov/portal/datasets/usps crosswalk.html.

${ }^{12}$ https://factfinder.census.gov, accessed August 2017.
} 
information about each utility's ownership, fuel sources, and the number of residential, commercial, and industrial customers. ${ }^{13}$

Figure 1 illustrates the data by describing two particular utilities with starkly contrasting rate structures. The flatter, dashed line plots summer electricity bills by consumption for households served by the Florida Keys Electric Cooperative. It has 26,792 customers and charges a simple two-part tariff: a fixed \$24 fee per month and $2.47 \not$ per $\mathrm{kWh}$. That is one of the least redistributive electricity tariffs in the country. The steeper, dotted line plots the bills for households in the Idaho Power Company. That utility has 432,275 customers and charges a fixed $\$ 5$ per month, $6.6 \varnothing$ per $\mathrm{kWh}$ for the first $800 \mathrm{kWh}$ in a month, $11.6 \varnothing$ for the next $1,200 \mathrm{kWh}$, and $13.6 \phi$ per $\mathrm{kWh}$ above 2,000. That is one of the most redistributive tariffs. The Florida utility charges more to low users, and the Idaho utility charges more to high users.

Our objective is to characterize those differences across all electric utilities in the US and to see whether those differences relate to the underlying income inequality of the utilities' ratepayers. The next step is to create a measure of the redistributive nature of the tariffs outlined in Table 1.

\section{A. Calculating the electric Gini}

To assess how each utility's tariff redistributes costs among ratepayers, we estimate what the hypothetical distribution of electricity bills would look like for each utility if it had customers that were representative of all US households. ${ }^{14}$ To construct those hypothetical electricity bills, we use data from the Residential Energy Consumption Survey (RECS), a nationally representative survey of more than 12,000 households conducted in 2009 by the US Department of Energy. ${ }^{15}$ The RECS reports annual electricity use, so we divide by 12 to get the average monthly kWh for each household. We then calculate how much that monthly use would cost, in August and January, in each of the 1,305 utilities for which we have matched income inequality data from the American Community Survey.

\footnotetext{
${ }^{13} \mathrm{https} / / / \mathrm{www}$. eia.gov/electricity/data/eia861/, accessed August 2017.

${ }_{14}$ Actual bills differ across utilities for two reasons: the utilities charge different tariffs, and the ratepayers choose different amounts of electricity. We want to focus solely on the tariff differences. The ratepayers' choices will themselves be a function of the tariffs, which is why we construct hypothetical bills based on representative ratepayers' choices.

${ }^{15}$ https://www.eia.gov/consumption/residential/.
} 
Those hypothetical sets of electricity bills vary across utilities solely based on differences in the utilities' rate structures. In service areas with high fixed monthly charges and low or declining per-kWh prices, households that use less electricity end up paying more, on average. In service areas with low monthly charges and high or increasing per-kWh prices, the heavy users pay more.

To quantify how redistributive those rate structures are, we plot Lorenz curves for the electricity bills from each utility, as if the RECS survey participants were customers of that utility. Figure 2 plots those electricity bill Lorenz curves for the two utilities in Figure 1. We start with a 10 percent sample of RECS households and calculate what those households' monthly summer electricity bills would be if they lived in each of the two service areas. ${ }^{16}$ The upper, dashed line in Figure 2 plots the resulting Lorenz curve for the Florida Keys utility. The lower, dotted line plots the Lorenz curve for the Idaho utility, which has a more redistributive rate structure. Households that use the least electricity pay a higher share of all costs in the Florida Keys service area than in Idaho.

For reference, the solid line in Figure 2 plots the share of electricity consumed by each percentile of the population. It is the same for each utility, by construction, since we used the same sample of hypothetical households in each service area. That solid line depicts what the electric bill Lorenz curve would look like if the utilities set a price per $\mathrm{kWh}$ equal to average cost. The Florida utility's electricity bills are more equally distributed than electricity consumption (the bill Lorenz curve lies above the solid electricity Lorenz curve). The Florida utility's tariff is regressive. For the Idaho utility, the reverse is true. Electricity bills are slightly more skewed toward high users than electricity consumption, and the bill Lorenz curve lies just below the electricity Lorenz curve. The Idaho utility's tariff is progressive.

Those electricity Lorenz curves can be used to calculate the electricity Gini coefficients that give this paper its title. The lower the Gini, the less redistributive the electricity prices. The Gini coefficient for the electricity bills of RECS households if they lived in the Florida Keys would be 0.17 . The electric Gini coefficient in Idaho would be 0.35 . Figure 3 plots histograms of all 1,305 utilities' electric Ginis for their summer rate structures. For comparison, Figure 3 also

\footnotetext{
${ }^{16}$ Jacobson et al. (2005) plot electricity consumption Lorenz curves, for different countries and regions of the US. We are plotting the electric bill Lorenz curves, for different utilities in the US but the same distribution of consumption.
} 
plots the distribution of household income Ginis. The income Ginis are larger, but the variation is similar.

The mission statements of utility regulators and our theoretical section above both suggest a positive correlation between the electric Ginis and income Ginis. In the next section, we look for that empirical relationship.

\section{B. Electric Ginis and income inequality}

In Table 2 we start by regressing the August electric Ginis, which measure the progressivity of local utilities' summer tariffs, on the household income Gini coefficients for the utilities' ratepayers, with no other covariates (column (2)). The coefficient on that income Gini $(0.149)$ is positive and statistically significant. Utilities that serve ratepayers with more unequal incomes have more progressive electricity prices - shifting more costs from low- to high-use ratepayers. We will discuss the magnitude of that effect in the next section, but first we examine other characteristics of utilities and their ratepayers that may be driving that correlation.

Although the coefficient is statistically significant, the income Ginis alone do not explain very much of the variation in electric Ginis.

Other candidate determinants of electricity tariff progressivity are poverty and average incomes. Column (3) substitutes the share of households below the federal poverty line in place of the household income Gini. That coefficient is insignificant and, if anything, wrong signed. Utilities serving more low-income customers redistribute less of their total cost from low to high users. In column (4), we substitute ratepayers' average household incomes. Utilities serving higher-income ratepayers redistribute more costs from low to high users, but that correlation is small. ${ }^{17}$

Column (5) of Table 2 adds other covariates. The first measures the effect of the tax and transfer system, in the state in which the utility's ratepayers reside, on the state income inequality. The variable is the difference in the state-level income Gini before and after taxes and transfers. On average, state fiscal policy reduces the income Gini by 0.065 (column (1)). It would

\footnotetext{
${ }^{17}$ We do not include all three income variables - income Gini, share below the poverty line, and average income-because including the latter two provides an alternative measure of the first. Places with more people in poverty, holding average income constant, have more income inequality.
} 
have been natural to expect states with progressive taxes and transfer policies, all else equal, to have less need for redistributive electricity prices. But the negative coefficient in column (5) suggests the opposite. More likely, the variable picks up the local taste for redistributive policy of all flavors. States that elect liberal-leaning legislators, who enact progressive tax and transfer policies, also appoint liberal-leaning utility regulators, who similarly enact progressive electricity tariffs. $^{18}$

Politics do not seem matter, as measured by the average democratic vote share in the last five presidential elections, once we account for other local ratepayer and utility characteristics. Electricity costs do matter, as measured by the average price (total revenues divided by $\mathrm{kWh}$ ). Places with more expensive electricity distribute more of the costs to high users, all else equal. Utilities with fewer commercial and industrial customers have less opportunity to cross-subsidize residential rates, which may explain why when the share of sales to residential customers is higher, electric Ginis are lower.

Column (6) adds three variables of particular interest. The first is a dummy for whether the utility also has a means-tested rate. About 8 percent of the utilities in our sample also have a special rate for eligible low-income ratepayers, in addition to the default tariff we are including in the regression. It would be natural to assume that utilities with means-tested rates would have less need for progressivity in the default tariffs they charge to non-poor ratepayers. The two policies - means-tested rates and progressive tariffs—-seem like substitutes. But the means-tested coefficient (0.006) suggests the opposite. As with the tax-and-transfer coefficient, we suspect the means-tested dummy captures a tendency to redistribute in all circumstances. Liberal-leaning utility regulators are more likely to promulgate means-tested rates and progressive default tariffs with high electric Ginis.

Next, many utilities and regulators express environmental concern in their mission statements and on their web pages. And those environmental concerns are often a justification for increasing block pricing - to encourage conservation by high demand households while protecting low users from steep price increases. ${ }^{19}$ So in column (6) we add a measure of local air

\footnotetext{
${ }^{18}$ One obvious concern is regional correlation. Appendix Figure F1 maps the regional distribution of income Gini coefficients. Appendix Figure F2 maps the electric Ginis. They do not appear to be regionally correlated. And versions of column (5) with region-fixed effects show similar results.

${ }^{19}$ Brolinson (2019).
} 
pollution: the number of years from 2010 to 2018 the local county violated national air quality standards for each of six criteria pollutants. ${ }^{20}$ The coefficient is positive, but quite small. An extra year of non-compliance with respect to one of the six pollutants is associated with an increase in the electric Gini of 0.001 .

The last covariate in column (6) is the correlation between household incomes and electricity use, from the 2009 RECS. ${ }^{21}$ If utilities or their regulators hope to favor low-income ratepayers, as opposed to low-electricity users who may or may not have low incomes, then that goal can be achieved by tariffs with high electric Ginis only if income and electricity use are correlated. In regions where the correlation is high, tariffs with high electric Ginis will favor low-income ratepayers. In regions where the correlation is low, high electric Ginis will end up granting low rates to high-income households that do not use much electricity and charging high rates to low-income households that happen to use a lot. We would expect, therefore, that the coefficient on that correlation would be positive. All else equal, if the correlation between income and electricity use is higher, electricity tariffs are a better tool for redistributing income. Instead, that coefficient $(-0.002)$ is small, statistically insignificant, and, if anything, negative. Although, when in the next step we add controls for the types of fuels used by each utility, this is the one coefficient that changes appreciably.

Column (7) of Table 2 adds the share of each utility's power generated from various fuel sources. Utilities generating more electricity from gas and nuclear have more redistributive tariffs. Utilities generating more from hydropower have less. ${ }^{22}$ Including all those fuel shares cuts the coefficient on the income Gini coefficient almost in half, but it remains statistically significant.

Table 3 adds weather to the regressions, on the theory that utility regulators' concern about income inequality will be greater if the utility's service area has hot summers and greater demand for air conditioning. In column (2) we replicate column (6) from Table 2, but add the number of cooling degree days. ${ }^{23}$ Places with a lot more cooling degree days per year have

\footnotetext{
${ }^{20}$ See https://www.epa.gov/green-book.

${ }^{21}$ See Appendix Figure F6.

22 The coal share serves as a benchmark. It is omitted from the regressions because for each utility, all the fuel shares add to one.

${ }^{23}$ A cooling degree day is the difference between the average of the daily maximum and minimum temperatures and $65^{\circ} \mathrm{F}$, when that average is greater than $65^{\circ}$.
} 
slightly more redistributive tariffs, and that relationship disappears once the full set of fuel shares and NERC indicators are added in column (3). But the coefficients on household income Ginis remain of similar magnitude and statistically significant.

Utilities serving customers with more unequal incomes have more redistributive tariffs, even after controlling for other local utility and ratepayer characteristics. Whether that relationship is economically significant is another question. ${ }^{24}$

\section{Magnitudes: How much do electricity prices redistribute income?}

It appears from Table 2 that electricity pricing serves a redistributive goal. Utilities whose ratepayers have more unequal incomes set prices more favorable to ratepayers who use less electricity. But how large is that redistribution? Figure 2 makes it seem as though that redistribution is large, because the electricity Lorenz curves differ so much across those two example utilities. But electricity bills are only one part of a households' costs, and electricity use is not perfectly correlated with income. So even though utilities whose ratepayers have unequal incomes may favor low users, that redistribution of costs among electricity users only redistributes income to the extent that electricity bills are large and correlated with income.

To illustrate this point, we again compare two utilities with contrasting tariffs. We do not want to use the same two utilities used in Figure 2-the Florida Keys Coop and Idaho Powerbecause they have very different electricity costs. The Idaho electricity is more expensive and therefore takes a larger share of households' budgets. That means electricity bills affect the netof-electricity incomes of Idaho Power ratepayers more than Florida Keys ratepayers, no matter how redistributional the two tariffs are. Instead, we limit our example to the set of utilities where, if ratepayers used electricity like typical households in the 2009 RECS, the average monthly electricity bill would be similar to the national average, $\$ 109$. Among those, the utility with the

\footnotetext{
${ }^{24}$ Appendix Table E1 presents a version of Table 2 for winter tariffs. There the relationship between income inequality and electricity tariff progressivity is smaller and less statistically significant, and it largely disappears once we include the full set of fuel shares and NERC region indicators in the last column.
} 
most redistributive tariff is the Village of Swanton, Vermont. The utility with the least redistributive tariff is the Missouri Rural Electric Cooperative. ${ }^{25}$

Figure 4 starts to assess the magnitude of the redistribution by plotting the electricity bills for these two example utilities, by decile of electricity consumption in the RECS data. The Village of Swanton, with the shaded columns, has a high electric Gini of 0.34, meaning it is favorable to low electricity users. It charges $\$ 8.14$ per month and then increasing block prices per kWh. The Missouri coop, with the outlined columns, has a low electric Gini of 0.24, meaning it is favorable to high electricity users. It charges $\$ 30$ per month and then decreasing block prices per $\mathrm{kWh}$. The difference in monthly bills depicted in Figure 4 is substantial. Low users of electricity would pay about \$25 more in the Missouri service area than in Swanton, about double. High users pay about $\$ 50$ per month less.

But Figure 4 characterizes the differences in electricity bills by household electricity use, not by household income. To compare the effect of the different tariffs on high-income and lowincome ratepayers, Figure 5 plots the same data as Figure 4, but reported by RECS income category rather than by decile of electricity use. Figure 5 makes the difference between the two utilities look much more modest. Low-income households would pay a few dollars more if they lived in the Missouri service area, and high-income households would pay a few dollars less.

Why does the plot of electricity bills by consumption decile look so much more redistributive than by income category? The implication is that income is not closely correlated with consumption.

Figure 6 illustrates this last point. It simply plots electricity use by income for the representative households in the RECS. The distribution is fairly flat. The highest-income households do use almost twice as much electricity as the lowest-income households, but they have 10 or 20 times as much income. Some high-income households use a small amount of electricity, and some low-income households use a large amount. Charging steeply rising block prices ends up favoring some high-income households that do not use very much electricity, and hurting some low-income households that use a lot.

\footnotetext{
${ }^{25}$ The Village of Swanton has 3,232 ratepayers, a fixed monthly charge of $\$ 8.14$, and block pricing that increases from $4.5 \phi$ per $\mathrm{kWh}$ to $11.2 \phi$. The Missouri Cooperative has a fixed monthly charge of $\$ 30$ and block pricing that decreases from $8.4 \phi$ to $7.5 \phi$ per $\mathrm{kWh}$. For reference, Appendix Figure F3 recreates the Lorenz curves from Figure 2 for these two other example utilities.
} 
Figure 7 presents this in even starker terms. We approximate households' incomes by taking midpoints of the income categories in the RECS. ${ }^{26}$ We then calculate the average electricity bill for households in each income category, for each utility, and subtract that bill from the approximated household incomes to get net-of-electricity incomes. Those net-ofelectricity incomes differ based solely on the different utilities' tariffs. We then calculate Gini coefficients for these net-of-electricity incomes. Figure 7 plots Lorenz curves for the same two example utilities used in Figure 4 and Figure 5. The effect of these two vastly different electricity pricing schemes has an almost unnoticeable effect on the distribution of net-of-electricity income. In the Missouri utility service area, the regressive, high-fixed-cost, decreasing-blockpricing tariff increases the household income Gini from 0.3956 before electricity bills to 0.4034 after. The Vermont utility's progressive, low-fixed-cost, increasing-block-pricing tariff also increases the household income Gini, but only to 0.4028 . We need to go to the fourth decimal place to see a difference. And it is imperceptible in Figure 7.

By contrast, Figure 8 plots the income Lorenz curves (without subtracting electricity bills) for each of the 27 geographic areas of the US identified in the 2009 RECS. The income Gini coefficients range from 0.32 for the most equal states (Idaho, Montana, Utah, and Wyoming) to 0.45 for the least equal states (Arkansas, Louisiana, and Oklahoma). Regions of the US differ far more in their income inequality than any redistribution among ratepayers within utilities depicted in Figure 7.

Again, progressive electricity tariffs shifts costs from low users of electricity to high users. But they do not necessarily shift costs from low-income ratepayers to high-income ratepayers. The reason is that income and electricity use are only weakly correlated. To illustrate that, Figure 9 plots the distribution of electricity use for the different income bins in the RECS data. ${ }^{27}$. High-income households do use more electricity than low-income ones; the thicker lines representing higher-income households are shifted to the right— but not by much. Many high-

\footnotetext{
${ }^{26}$ The categories are those listed on the bottom axis of Figure 5. We arbitrarily assume the average income in the top-coded category to be $\$ 135,000$.

${ }^{27}$ The idea for this figure came from Brolinson (2019), which contains a similarly drawn figure using ratepayer data from two utilities in California.
} 
income households spend very little on electricity, and a lot of low-income ones pay high electric bills. $^{28}$

Why is the correlation between electricity and income so low? We can think of two explanations with empirical support. First, high-income households spend less time at home. People who live in households with incomes between $\$ 10,000$ and $\$ 20,000$ are home more than 50 percent of the time. In households with incomes above $\$ 150,000$, that drops below 40 percent. ${ }^{29}$ Time at home cannot entirely explain why electricity and income are so uncorrelated, but it is surely part of the story.

Another part of the explanation may involve energy efficiency investments. In theory, we should expect higher-income households to insulate their homes better and to buy more efficient appliances, and in practice that is what we see (Levinson, 2019). Homes occupied by higherincome residents have more insulation, better windows, more efficient lighting, and appliances that are more likely to be classified as "Energy Star" by the US Department of Energy.

\section{Conclusions}

Public utility regulators in the US claim that they set electricity prices with a goal of protecting the well-being of low-income ratepayers. We show that in theory, regulators who care only about efficiency — not equity — will charge a simple two-part tariff: per-kWh volumetric prices equal to the marginal cost of providing electricity, and some fixed monthly fees to cover any remaining fixed costs of power plants and transmission lines. But regulators who care about income inequality, and who cannot simply vary the fixed monthly fee on a household-byhousehold basis, will charge higher-than-efficient per-kWh prices and lower monthly fees.

Perhaps surprisingly, in practice that is exactly what happens. Across the US utilities serving customers with more unequal incomes depart more from the efficient two-part tariff, charging higher or increasing per-kWh prices and lower fixed monthly fees. Utilities appear to be doing what their mission statements claim.

\footnotetext{
${ }^{28}$ Figure 9 depicts distributions of annual averages for the whole country. That aggregation may mask some of the correlation if, for example, low-income households use more electricity for heating during winters in the Midwest, or for air conditioning during summers in the Southwest. Appendix Figure F4 plots a similar set of distributions of electricity use by income, but restricted only to one utility and one month's bills: California's PG\&E customers in August. It shows the same thing: a remarkably low correlation between electricity use and income.

${ }^{29}$ Figure F5 plots time at home by household income, using the 2017 American Time Use Survey.
} 
Those efforts may be less than effective, however, because income and electricity consumption are so weakly correlated. When utilities redistribute income by raising per-kWh prices and lowering monthly fees, they do shift costs from low users of electricity to high users. But that does not necessarily shift costs from low-income households to high-income ones. Electricity pricing is an indirect tool for addressing income inequality. Perhaps unsurprisingly, it is also not an effective tool.

\section{References}

Bonbright, James. 1988. Principles of Public Utility Rates, $2^{\text {nd }}$ Edition. Arlington, Va : Public Utilities Reports, Inc.

Borenstein, Severin. 2012. "The Redistributional Impact of Nonlinear Electricity Pricing" American Economic Journal: Economic Policy 4(3).

Borenstein, Severin. 2016. "The Economics of Fixed Cost Recovery by Utilities" The Electricity Journal 29: 5-12.

Borenstein, Severin and James Bushnell. 2018. "Do Two Electricity Pricing Wrongs Make a Right? Cost Recovery, Externalities, and Efficiency” NBER Working Paper 24756.

Borenstein, Severin and Lucas Davis. 2012. "The Equity and Efficiency of Two-Part Tariffs in U.S. Natural Gas Markets” Journal of Law and Economics 55(1): 75-128.

Brolinson, Becka. 2019. "Does Increasing Block Pricing Decrease Electricity Consumption?” Georgetown University Economics Department Working Paper.

Burger, Scott, Christopher Knittel, Ignacio Pérez-Arriaga, Ian Schneider, and Frederik Vom Scheidt. 2019. "The Efficiency and Distributional Effects of Alternative Residential Electricity Rate Designs" MIT Center for Energy and Environmental Policy Research Working Paper 2019-002.

Coase, Ronald H. 1946. “The Marginal Cost Controversy.” Economica 13: 169-182.

Feger, Fabian and Doina Radulescu. 2018. "Redistribution through Income Taxation and Public Utility Pricing in the Presence of Energy Efficiency Considerations" CESifo Working Paper 7195.

Feldstein, Martin. 1972. "Equity and Efficiency in Public Sector Pricing: The Optimal Two-Part Tariff" Quarterly Journal of Economics 86:175-87. 
Gormley, William. 1983. The Politics of Public Utility Regulation. Pittsburgh, PA: University of Pittsburgh Press.

Hotelling, Harold. 1938. "The General Welfare in Relation to Problems of Taxation and of Railway and Utility Rates” Econometrica 3:242-269.

Ito, Koichiro. 2014. "Do Consumers Respond to Marginal or Average Price? Evidence from Nonlinear Electricity Pricing" American Economic Review 104 (2): 537-63.

Jacobson, Arne, Anita D. Milman, and Daniel M. Kammen. 2005. "Letting the (energy) Gini out of the bottle: Lorenz curves of cumulative electricity consumption and Gini coefficients as metrics of energy distribution and equity" Energy Policy 33(14): 1825-1832.

Levinson, Arik. 2019. "Energy Efficiency Standards Are More Regressive Than Energy Taxes: Theory and Evidence" Journal of the Association of Environmental and Resource Economists, 6(S1): 7-36.

World Bank. 2017. "Electricity tariffs for nonresidential customers in Sub-Saharan Africa" Washington, DC: World Bank Group.

Zhang, Zibin, Wenxin Cai, and Xiangzhao Feng. 2017. "How do urban households in China respond to increasing block pricing in electricity? Evidence from a fuzzy regression discontinuity approach" Energy Policy 105: 161-172. 
Table 1. Characteristics of US Residential Electricity Bills

\begin{tabular}{|c|c|c|c|}
\hline & Rates & Thresholds & Utilities \\
\hline & (Average \$) & (Average kWh) & (n) \\
\hline \multicolumn{4}{|l|}{ Summer rates } \\
\hline First tier & 0.099 & & 1,305 \\
\hline Second & 0.105 & 686 & 514 \\
\hline Third & 0.110 & 1,502 & 217 \\
\hline Fourth & 0.120 & 2,129 & 54 \\
\hline Fifth & 0.124 & 1,490 & 23 \\
\hline Sixth & 0.085 & 1,933 & 3 \\
\hline Increasing block prices & & & 246 \\
\hline Decreasing block prices & & & 255 \\
\hline \multicolumn{4}{|l|}{ Winter rates } \\
\hline First tier & 0.098 & & 1,305 \\
\hline Second & 0.095 & 687 & 583 \\
\hline Third & 0.101 & 1,499 & 232 \\
\hline Fourth & 0.113 & 2,101 & 52 \\
\hline Fifth & 0.123 & 1,441 & 22 \\
\hline Sixth & 0.079 & 1,950 & 4 \\
\hline Increasing block prices & & & 177 \\
\hline Decreasing block prices & & & 394 \\
\hline \multicolumn{4}{|l|}{ Fixed Monthly Charge } \\
\hline & $\$ 14.22$ & & 1,254 \\
\hline
\end{tabular}


Table 2. Summer Electricity Gini and Local Population Characteristics

Means

\begin{tabular}{|c|c|c|c|c|c|c|c|}
\hline Variables & (1) & (2) & (3) & (4) & (5) & (6) & (7) \\
\hline Household income & $0.444^{*}$ & $0.149 *$ & & & $0.164 *$ & $0.137^{*}$ & $0.071^{*}$ \\
\hline Gini 2015 & $(0.001)$ & $(0.032)$ & & & $(0.028)$ & $(0.028)$ & $(0.028)$ \\
\hline \multirow{2}{*}{$\begin{array}{l}\text { Share below } \\
\text { poverty line }\end{array}$} & $0.189 *$ & & -0.011 & & & & \\
\hline & $(0.002)$ & & $(0.013)$ & & & & \\
\hline \multirow{2}{*}{$\begin{array}{l}\text { Average income } \\
\qquad(\$ 10,000)\end{array}$} & $6.436^{*}$ & & & $0.005^{*}$ & $0.002 *$ & -0.000 & 0.000 \\
\hline & $(0.038)$ & & & $(0.001)$ & $(0.001)$ & $(0.001)$ & $(0.001)$ \\
\hline \multirow{2}{*}{$\begin{array}{c}\text { State tax/transfer } \\
\text { effect on Gini }\end{array}$} & $-0.065 *$ & & & & $-0.860 *$ & $-0.793^{*}$ & $-0.983^{*}$ \\
\hline & $(0.000)$ & & & & $(0.179)$ & $(0.177)$ & (0.179) \\
\hline \multirow{2}{*}{$\begin{array}{l}\text { Democratic vote } \\
\text { share }\end{array}$} & $0.389 *$ & & & & 0.013 & 0.009 & 0.008 \\
\hline & $(0.003)$ & & & & $(0.007)$ & $(0.007)$ & $(0.007)$ \\
\hline \multirow{2}{*}{$\begin{array}{l}\text { Fraction of sales } \\
\text { residential }\end{array}$} & $0.453^{*}$ & & & & $-0.023^{*}$ & $-0.024 *$ & $-0.023^{*}$ \\
\hline & $(0.005)$ & & & & $(0.004)$ & $(0.004)$ & (0.004) \\
\hline \multirow{2}{*}{$\begin{array}{l}\text { Res. customers } \\
\text { (mill.) }\end{array}$} & $0.057^{*}$ & & & & $0.009 *$ & 0.006 & 0.004 \\
\hline & $(0.006)$ & & & & $(0.004)$ & $(0.004)$ & $(0.004)$ \\
\hline \multirow{2}{*}{$\begin{array}{l}\text { Average electricity } \\
\text { price }(\$ / \mathrm{kWh})\end{array}$} & $0.107 *$ & & & & $0.179 *$ & $0.148^{*}$ & $0.095^{*}$ \\
\hline & $(0.001)$ & & & & $(0.028)$ & $(0.028)$ & $(0.031)$ \\
\hline \multirow{2}{*}{$\begin{array}{l}\text { Investor owned } \\
\text { utility }\end{array}$} & $0.080^{*}$ & & & & 0.002 & 0.000 & 0.001 \\
\hline & $(0.008)$ & & & & $(0.003)$ & $(0.003)$ & $(0.003)$ \\
\hline \multirow[t]{2}{*}{ Cooperative } & $0.375 *$ & & & & $-0.029 *$ & $-0.027^{*}$ & $-0.026^{*}$ \\
\hline & $(0.013)$ & & & & $(0.002)$ & $(0.002)$ & $(0.002)$ \\
\hline \multirow{2}{*}{$\begin{array}{l}\text { Has a means } \\
\text { tested rate }\end{array}$} & $0.077^{*}$ & & & & & $0.006^{*}$ & $0.006^{*}$ \\
\hline & $(0.007)$ & & & & & $(0.003)$ & $(0.003)$ \\
\hline \multirow{2}{*}{$\begin{array}{r}\text { Noncompliance } \\
\text { with NAAQS }\end{array}$} & $2.352 *$ & & & & & $0.001 *$ & $0.001 *$ \\
\hline & $(0.162)$ & & & & & $(0.000)$ & $(0.000)$ \\
\hline \multirow{2}{*}{$\begin{array}{l}\text { Correlation } \\
\quad \text { (income, elect) }\end{array}$} & $0.316^{*}$ & & & & & 0.002 & $-0.024^{*}$ \\
\hline & $(0.002)$ & & & & & $(0.010)$ & $(0.011)$ \\
\hline \multirow{2}{*}{$\begin{array}{l}\text { Share electricity } \\
\text { from gas }\end{array}$} & $0.175^{*}$ & & & & & & $0.037^{*}$ \\
\hline & $(0.005)$ & & & & & & $(0.005)$ \\
\hline \multirow{2}{*}{$\begin{array}{l}\text { Share electricity } \\
\text { from nuclear }\end{array}$} & $0.185^{*}$ & & & & & & $0.016^{*}$ \\
\hline & $(0.004)$ & & & & & & $(0.005)$ \\
\hline \multirow{2}{*}{$\begin{array}{l}\text { Share electricity } \\
\text { from hydro }\end{array}$} & $0.069 *$ & & & & & & -0.008 \\
\hline & $(0.004)$ & & & & & & $(0.005)$ \\
\hline \multirow{2}{*}{$\begin{array}{l}\text { Share electricity } \\
\text { from petroleum }\end{array}$} & $0.007^{*}$ & & & & & & 0.022 \\
\hline & $(0.001)$ & & & & & & (0.019) \\
\hline \multirow[t]{2}{*}{ Constant } & & $0.234 *$ & $0.303^{*}$ & $0.268^{*}$ & $0.158^{*}$ & $0.187^{*}$ & $0.208^{*}$ \\
\hline & & $(0.014)$ & $(0.003)$ & $(0.004)$ & $(0.019)$ & $(0.019)$ & $(0.019)$ \\
\hline$N$ & 1,305 & 1,305 & 1,305 & 1,305 & 1,305 & 1,305 & 1,305 \\
\hline $\mathrm{R} 2$ & & 0.02 & 0.00 & 0.05 & 0.38 & 0.41 & 0.44 \\
\hline
\end{tabular}

Notes: Column (1) reports the means and standard deviations of all variables. Asterisks $\left({ }^{*}\right)$ denote statistically significance at $5 \%$. 
Table 3. Summer Electricity Ginis and Local Weather

\begin{tabular}{lccc} 
& Means & \multicolumn{2}{c}{ Regressions } \\
\hline Variables & $\mathbf{( 1 )}$ & $\mathbf{( 2 )}$ & $\mathbf{( 3 )}$ \\
\hline Household income Gini & $0.444^{*}$ & $0.091^{*}$ & $0.062^{*}$ \\
$\quad 2015$ & $(0.001)$ & $(0.029)$ & $(0.029)$ \\
Cooling degree days & $1.214^{*}$ & $0.0057^{*}$ & -0.0017 \\
$\quad$ per year (1000) & $(0.021)$ & $(0.0011)$ & $(0.0013)$ \\
Other covariates from & & yes & yes \\
$\quad$ col (6) of Table 2 & & & \\
Utility type dummies & & & yes \\
& & & 1,305 \\
$N$ & 1,305 & 1,305 & 0.44 \\
R2 & & 0.42 & 0.4
\end{tabular}

Notes: Column (1) reports the means and standard deviations.

Asterisks $\left({ }^{*}\right)$ denote statistically significance at $5 \%$.

Figure 1. Example Utility Bills

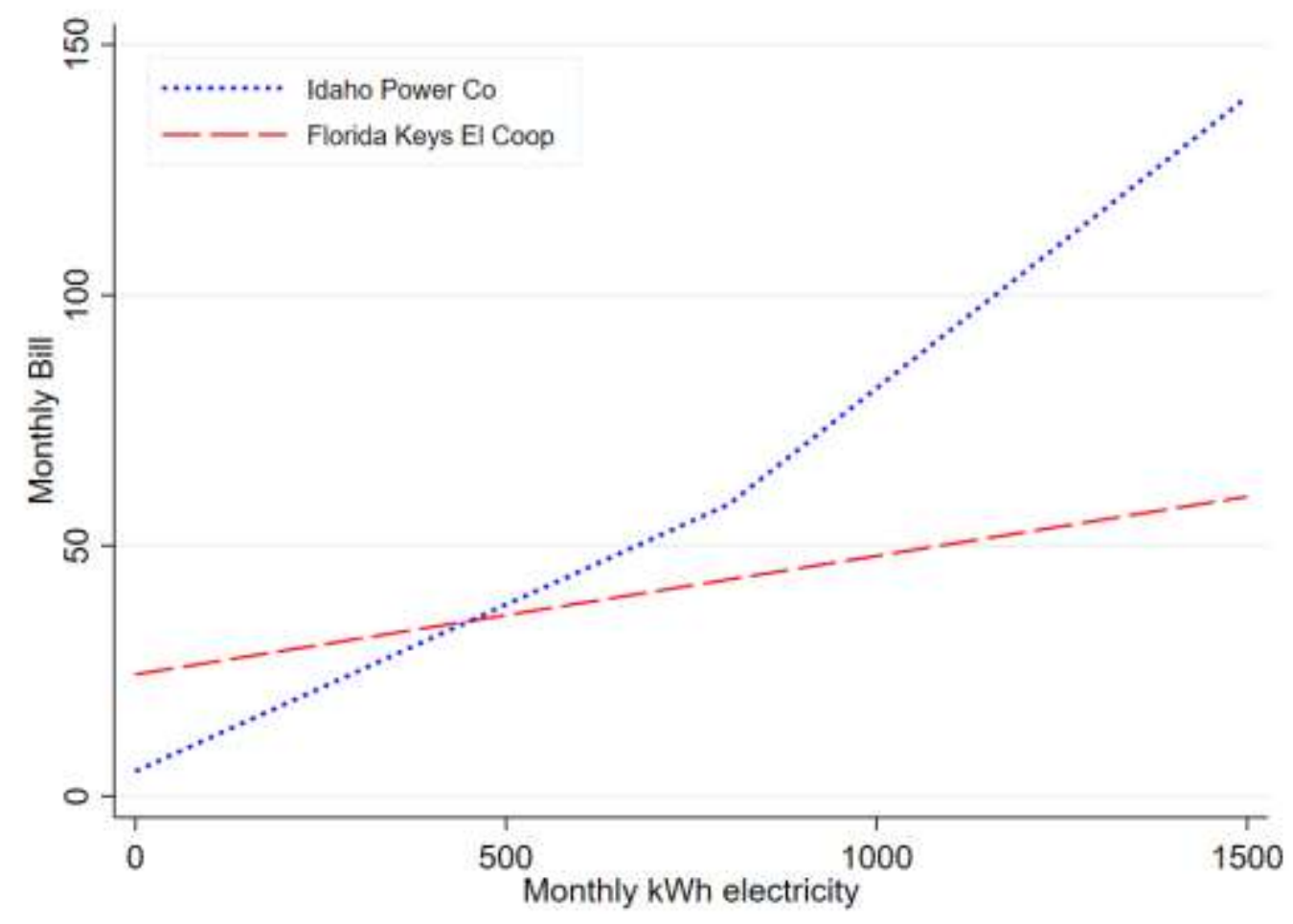


Figure 2. Electricity Lorenz Curves for Example Utilities

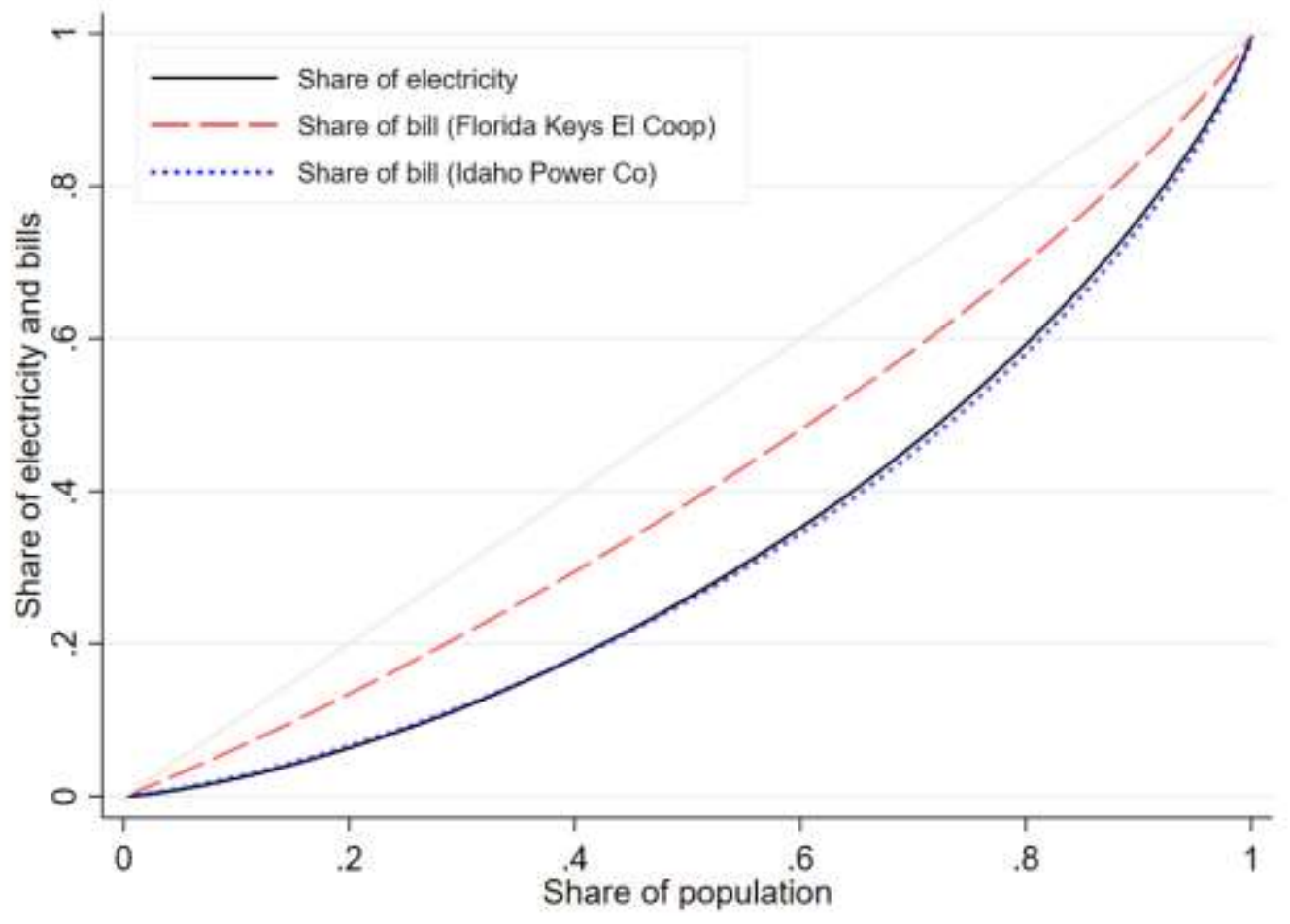

Figure 3. Distribution of Electric Ginis and Household Income Ginis

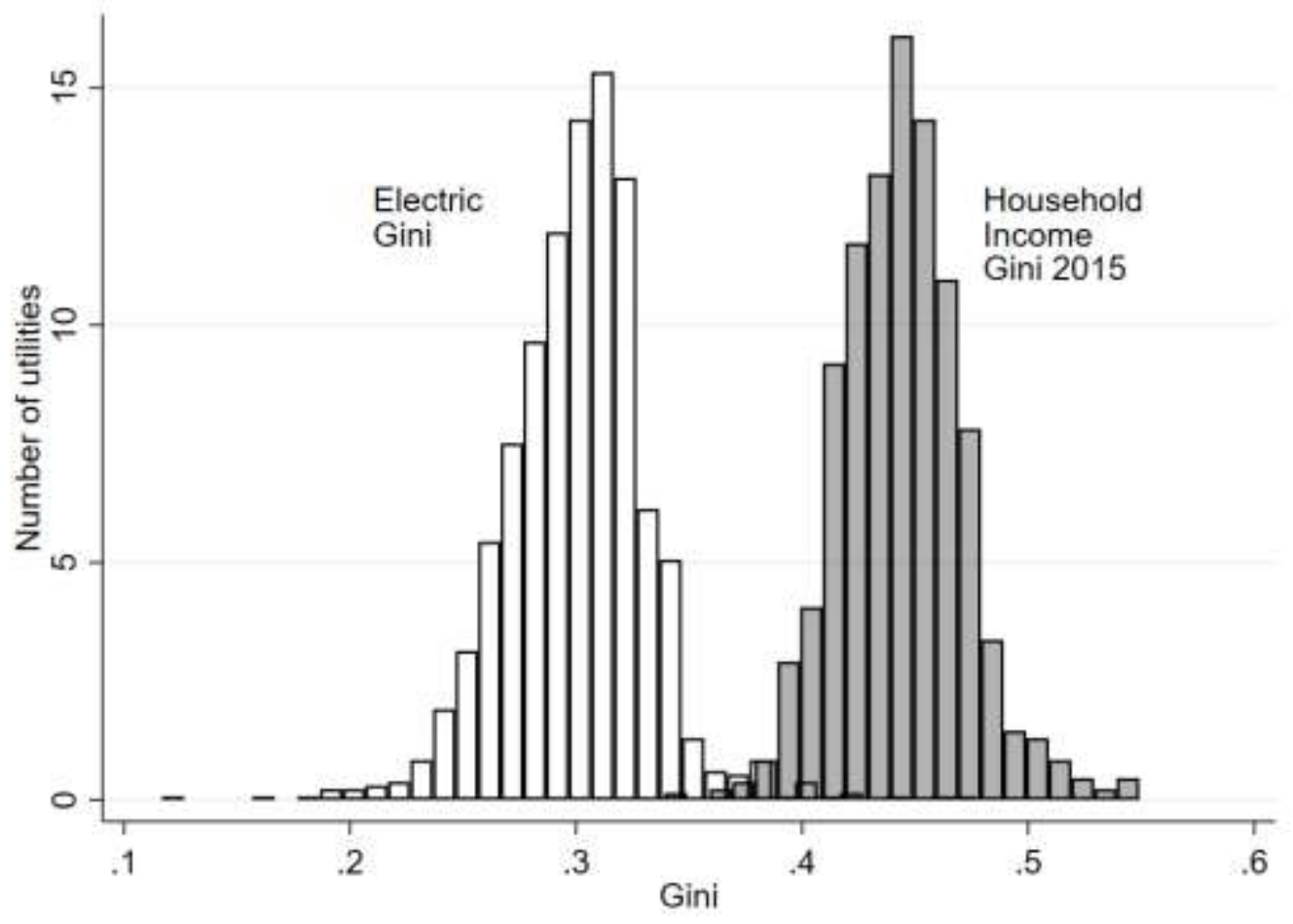


Figure 4. Average Electricity Bills for Two Particular Utilities, by Electricity Use

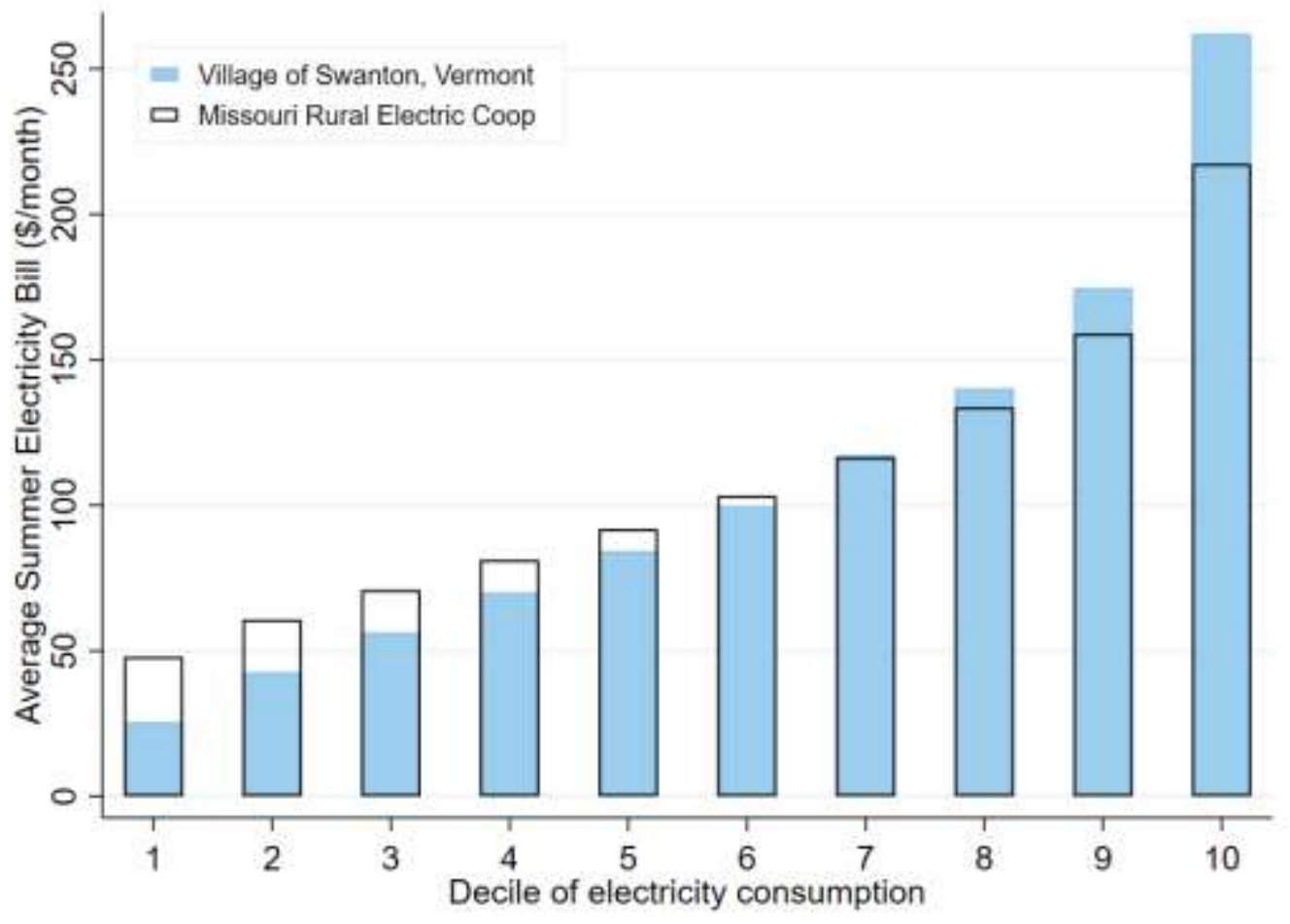

Figure 5. Average Electricity Bills for Two Particular Utilities, by Income

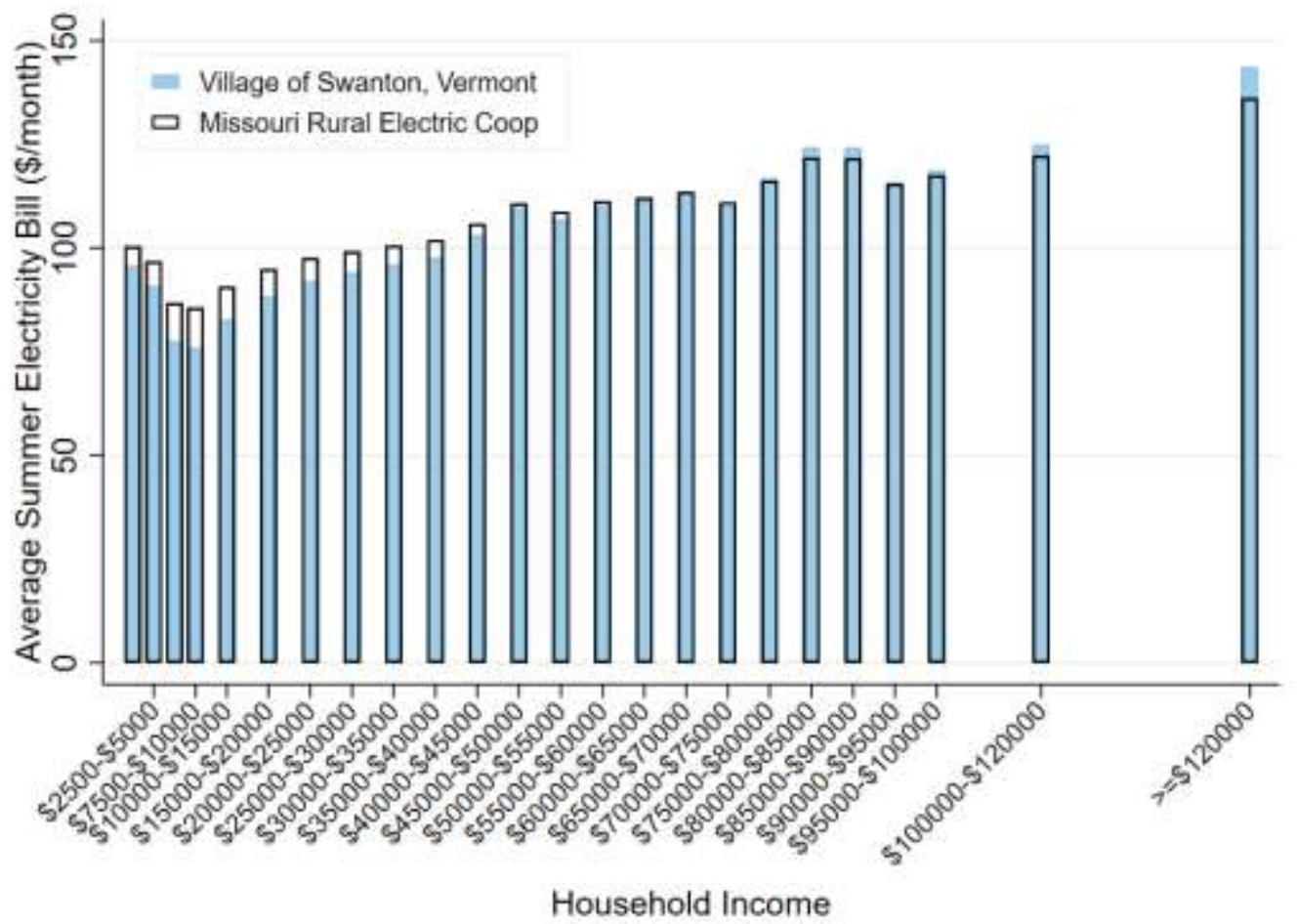


Figure 6. Electricity Use by Income: RECS 2009

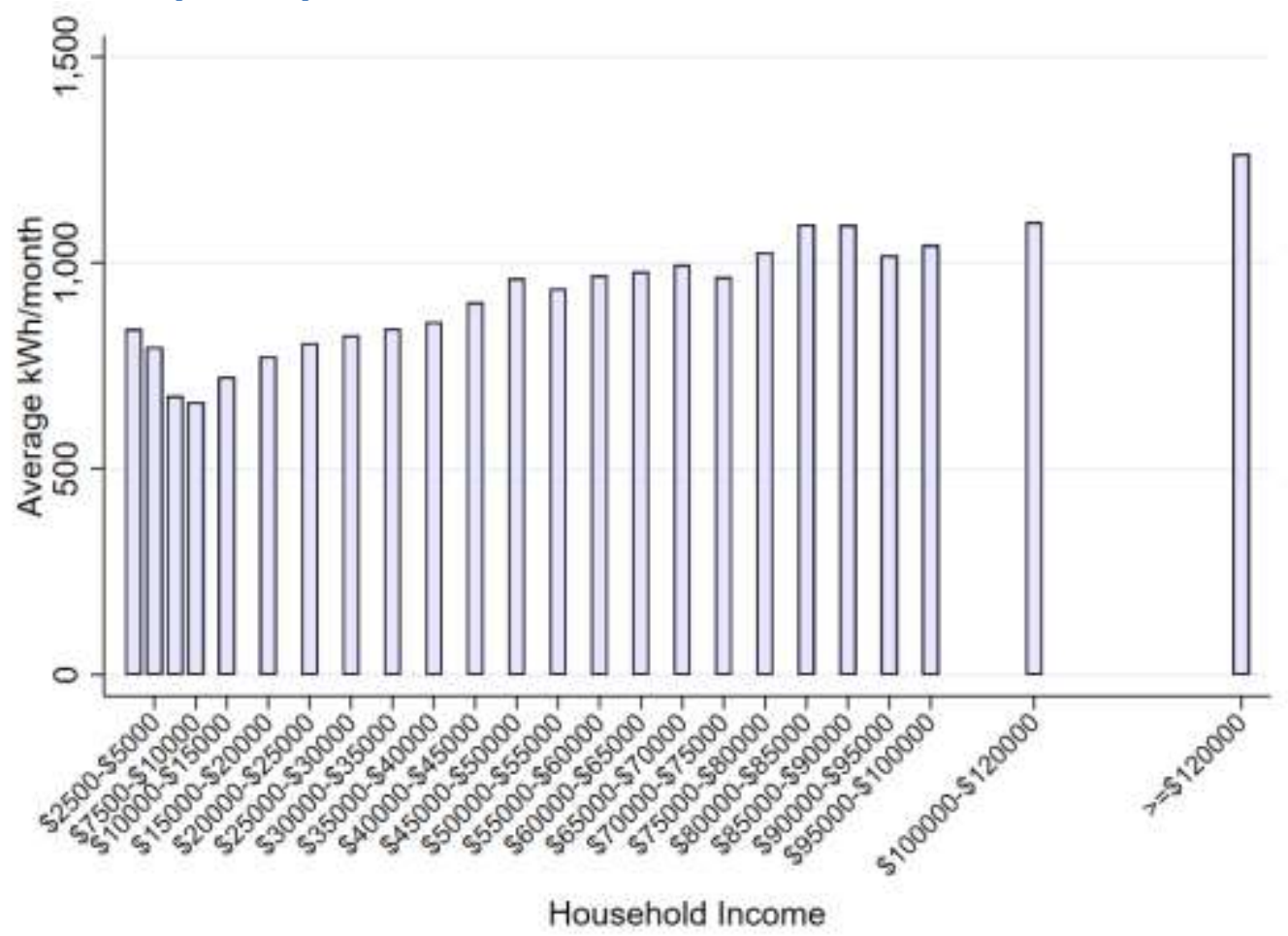

Figure 7. Lorenz Curves by Net-of-Electricity Income for Two Particular Utilities

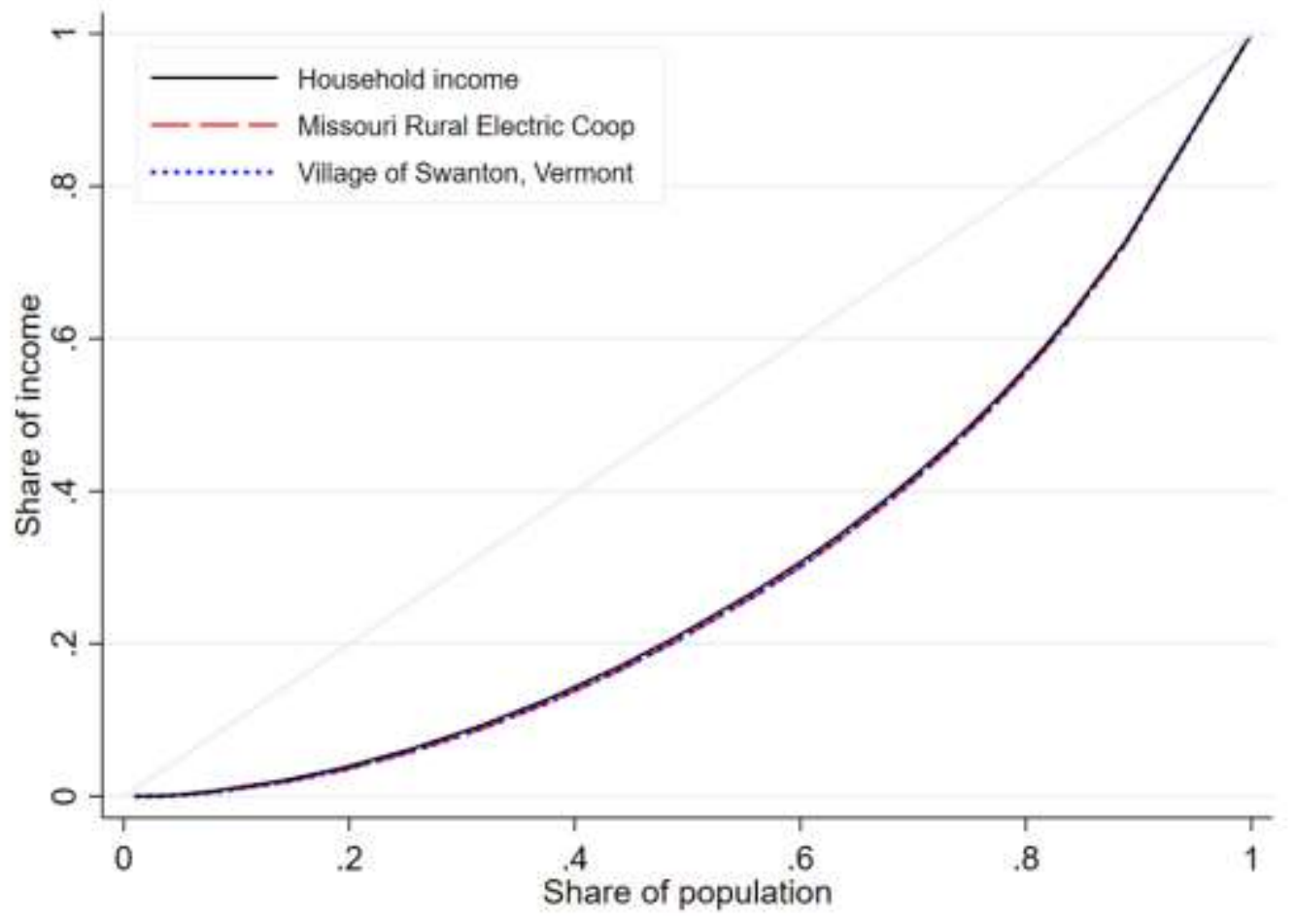


Figure 8. Income Lorenz Curves by Groups of States

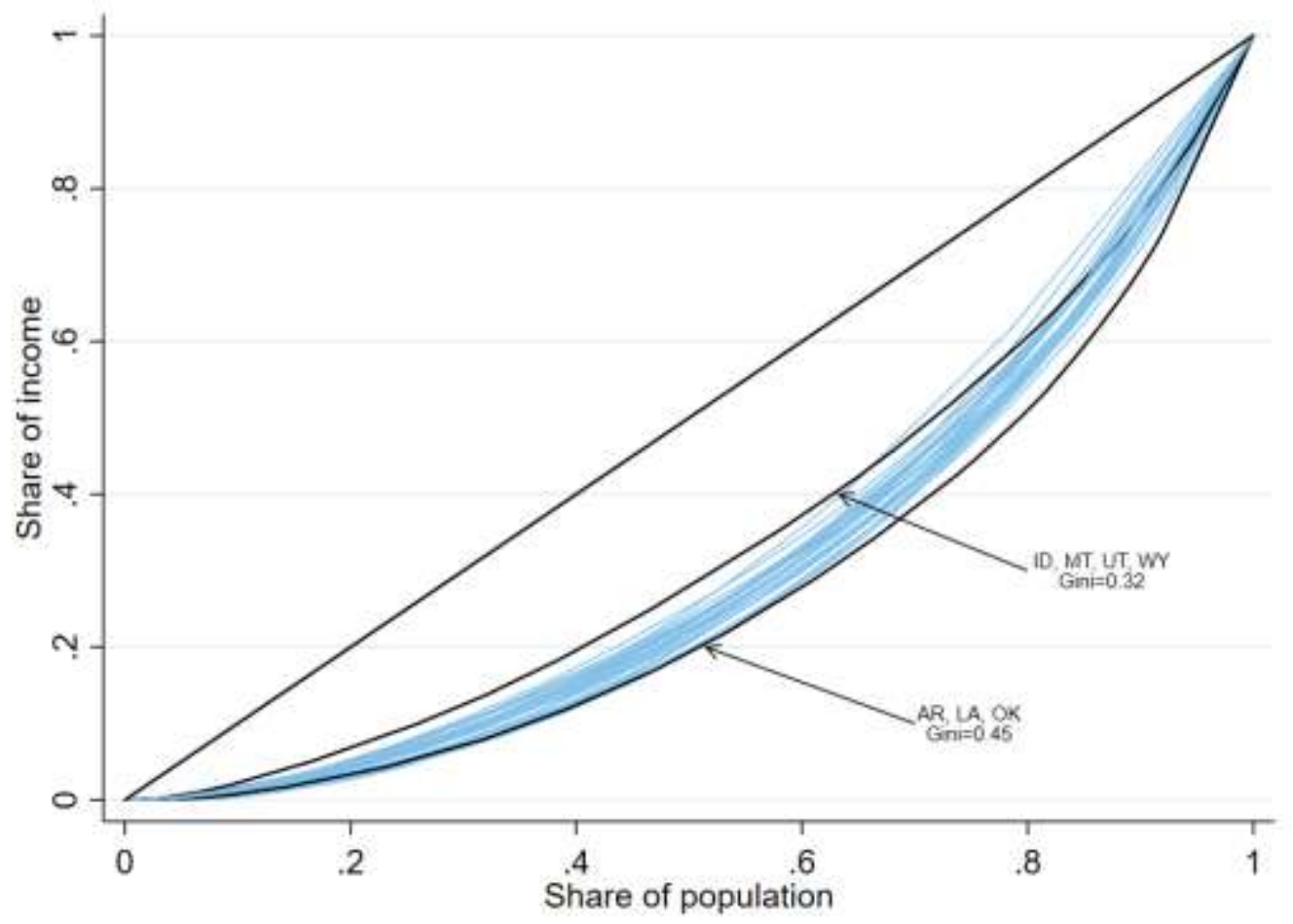

Source: Authors' calculations from 2009 RECS.

Figure 9. Distributions of Electricity Use by Household Income

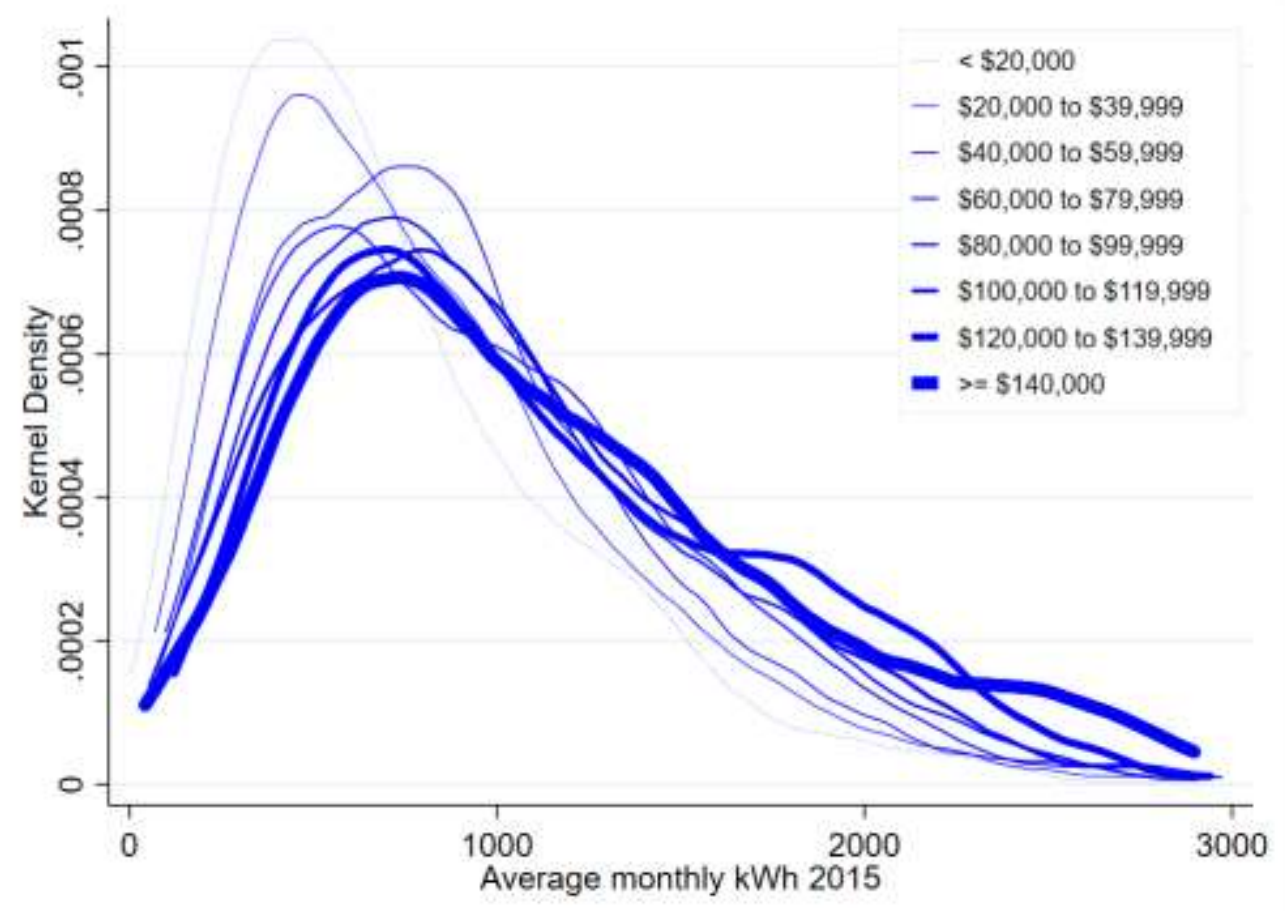

Source: Authors' calculations from 2009 RECS. 


\section{Appendices}

\section{A. First-Best: Individualized Prices and Access Fees}

Consider an economy with $n$ households, distinguished according to their income levels. Let $w^{i}$ denote the income level of a household of $i, i=1, \ldots, n$. Household $i$ derives utility $u\left(e^{i}, x^{i}\right)$ from consumption of $x^{i}$ units of a numeraire good and $e^{i}$ units of electricity, where $u_{x}>0, u_{e}>0, u_{x x}<0, u_{e e}<0, u_{x e} \geq 0, u_{x x} u_{e e} \geq u_{x e}^{2}$. The household's budget constraint is $x^{i}+p^{i} e^{i}=\hat{w}^{i} \equiv w^{i}-t^{i}$, where $p^{i}$ is the price faced this household per unit of electricity and $t^{i}$ is a fixed fee the household pays to have access to the electricity system. We allow the electricity and access fee to be personalized in order to study departures from the first-best when the regulator faces constraints that make it impossible to personalize the access fee and the electricity price.

Taking the access fee and the price of electricity as given, household $i$ chooses the amount of electricity to consume in order to maximize $u\left(e^{i}, \hat{w}^{i}-p^{i} e^{i}\right)$. Assuming an interior solution, the first-order condition yields

$$
\frac{u_{e}^{i}}{u_{x}^{i}}=p^{i}, \quad i=1, \ldots, n,
$$

where $u_{x}^{i} \equiv \partial u\left(e^{i}, x^{i}\right) / \partial x^{i}$ and $u_{e}^{i} \equiv \partial u\left(e^{i}, x^{i}\right) / \partial e^{i}$. Let $e^{i}\left(p^{i}, \hat{w}^{i}\right)$ and $x^{i}\left(p^{i}, \hat{w}^{i}\right)=\hat{w}^{i}-p^{i} e^{i}\left(p^{i}, \hat{w}^{i}\right)$ denote the quantities demanded of electricity and numeraire good, respectively. Household $i$ 's indirect utility function is

$$
v\left(p^{i}, \hat{w}^{i}\right)=u\left(x^{i}\left(p^{i}, \hat{w}^{i}\right), e^{i}\left(p^{i}, \hat{w}^{i}\right)\right), \quad i=1, \ldots, n
$$

The electricity supplier can produce $E$ units of output at the total cost $F+c E$, where $F>0$ is the fixed cost and $c>0$ is the per unit cost. In any equilibrium, $E=\sum_{i=1}^{n} e^{i}\left(p^{i}, \hat{w}^{i}\right)$, since the quantity supplied must be equal to the quantity demanded.

Electricity supply is regulated. The regulator chooses $\left\{p^{1}, \ldots, p^{n}, t^{1}, \ldots, t^{n}\right\}$ to maximize $\sum_{i=1}^{n} v\left(p^{i}, w^{i}-t^{i}\right)$ subject to the following feasibility constraint:

$$
\sum_{i=1}^{n}\left[t^{i}+\left(p^{i}-c\right) e^{i}\left(p^{i}, w^{i}-t^{i}\right)\right]=F
$$


Letting $\lambda$ denote the multiplier associated with constraint (A3), the first-order conditions are equation (A3) and the following, for $j=1, \ldots, n$ :

$$
\begin{gathered}
-v_{p}^{j}=\lambda\left(e^{j}+\left(p^{j}-c\right) e_{p}^{j}\right) \quad\left(\text { with respect to } p^{j}\right) \text { and } \\
v_{\hat{w}}^{j}=\lambda\left(1-\left(p^{j}-c\right) e_{\hat{w}}^{j}\right) \quad\left(\text { with respect to } t^{j}\right),
\end{gathered}
$$

where $v_{p}^{j} \equiv \partial v\left(p^{j}, \hat{w}^{j}\right) / \partial p^{j}, v_{\hat{w}}^{j} \equiv \partial v\left(p^{j}, \hat{w}^{j}\right) / \partial \hat{w}^{j}, e_{p}^{j} \equiv \partial e^{j}\left(p^{j}, \hat{w}^{j}\right) / \partial p^{j}$ and $e_{\hat{w}}^{j} \equiv \partial e^{j}\left(p^{j}, \hat{w}^{j}\right) / \partial \hat{w}^{j}$.

Combining equations (A4) and (A5) in order to eliminate the multiplier yields, for $j=1, \ldots, n$

$$
-\frac{v_{p}^{j}}{v_{\hat{w}}^{j}}=\frac{e^{j}+\left(p^{j}-c\right) e_{p}^{j}}{1-\left(p^{j}-c\right) e_{\hat{w}}^{j}}>0
$$

Roy's identity $\left(-v_{p}^{j} / v_{\hat{w}}^{j}=e^{j}\right)$ means that the left side of equation (A6) equals $e^{j}, \forall j$. That in turn means that

$$
\left(p^{j}-c\right)\left[e^{j} e_{\hat{w}}^{j}+e_{p}^{j}\right]=0
$$

By the Slutsky equation, the term in square brackets in (A7) is the derivative of the Hicksian electricity demand function, which is strictly negative for any well-behaved preferences: $h_{p}^{j} \equiv \partial h^{j}\left(p^{j}, u^{j}\right) / \partial p^{j}<0$. So

$$
\left(p^{j}-c\right) h_{p}^{j}=0 \Rightarrow p^{j}-c=0 \text {. }
$$

Every household is charged the same price, $p^{j}=c$.

Since $v_{w}^{j}=u_{x}^{j}, \forall j$, equations (A5) and (A8) imply

$$
u_{x}^{j}=u_{x}^{i}, \quad \forall i, j=1, \ldots, n, i \neq j
$$

Since $p^{j}=c, \forall j$, equations (A1) imply

$$
u_{e}^{j}=u_{e}^{i}, \quad \forall i, j=1, \ldots, n, i \neq j .
$$

Equations (A9) and (A10) hold simultaneously if and only if, for $\forall i, j=1, \ldots, n, i \neq j$ : 


$$
\begin{aligned}
& e^{i}=e^{j}, \\
& x^{i}=x^{j} .
\end{aligned}
$$

Now, note that equations (A11) and (A12) imply

$$
\hat{w}^{i} \equiv w^{i}-t^{i}=w^{j}-t^{j} \equiv \hat{w}^{j}, \quad \forall i, j=1, \ldots, n, i \neq j
$$

If $w^{i}=w^{j}, \forall i, j=1, \ldots, n, i \neq j$, then equations (A13) imply $t^{i}=t^{j}=t$. In this case, $t=F / n$ according to (A3).

\section{B. Uniform Access Fees and Individualized Prices}

Consider the case where the regulator can set individual prices, $p^{i}$, but cannot set individualized access fees: $t^{i}=t$ for all $i$. The regulator chooses $\left\{p^{i}, \ldots, p^{n}, t\right\}$ to maximize $\sum_{i} v\left(p^{i}, w^{i}-t\right)$ subject to

$$
n t+\sum_{i}\left(p^{i}-c\right) e^{i}\left(p^{i}, w^{i}-t\right)=F
$$

Letting $\lambda$ denote the multiplier associated with constraint (B1), and assuming an interior solution $\left(t>0\right.$ and $\left.p^{j}>0\right)$, the first-order conditions are (A4) and

$$
\sum_{i} v_{\hat{w}}^{i}=\lambda\left(n-\sum_{i}\left(p^{i}-c\right) e_{\hat{w}}^{i}\right)
$$

Since $\lambda>0$ and $\sum_{i} v_{\hat{w}}^{i}>0, n-\sum_{i}\left(p^{i}-c\right) e_{\hat{w}}^{i}>0$. Combining conditions (A4) and (B2) yields

$$
\sum_{i} v_{\hat{w}}^{i}=-\left(\frac{v_{p}^{j}}{e^{j}+\left(p^{i}-c\right) e_{p}^{j}}\right)\left(n-\sum_{i}\left(p^{i}-c\right) e_{\hat{w}}^{i}\right), \quad \forall j .
$$

Using Roy's identity, $-v_{p}^{j}=e^{j} v_{\hat{w}}^{j}$, and cross-multiplying by $\left(e^{j}+\left(p^{j}-c\right) e_{p}^{j}\right) / e^{j}$, equations (B3) then imply

$$
L^{j} \equiv \frac{p^{j}-c}{p^{j}}=-\frac{1}{\varepsilon_{p}^{j}}\left[1-\frac{v_{\hat{w}}^{j}\left(n-\sum_{i}\left(p_{i}-c\right) e_{\hat{w}}^{i}\right)}{\sum_{i} v_{\hat{w}}^{i}}\right], \quad \forall j
$$

which is equation (12) in the main body of the paper. 


\section{Solar Roofs and Other Electricity Endowments}

To capture non-income heterogeneity, we assume household $i$ is endowed with $\tilde{e}^{i}$ units of electricity. Household $i$ 's budget constraint is then $x^{i}+p^{i}\left(e^{i}-\tilde{e}^{i}\right)=w^{i}-t$. Define $\tilde{w}^{i}$ as the household's exogenous income, including the value of its electricity endowment and net of access fees: $\tilde{w}^{i} \equiv w^{i}+p^{i} \tilde{e}^{i}-t$. Household $i^{\prime \prime}$ s electricity demand is $e^{i}\left(p^{i}, \tilde{w}^{i}\right)$ and indirect utility is $v^{i}\left(p^{i}, \tilde{w}^{i}\right)$. The regulator chooses $\left\{p^{l}, \ldots, p^{n}, t\right\}$ to maximize $\sum_{i} v^{i}\left(p^{i}, \tilde{w}^{i}\right)$, subject to

$$
n t+\sum_{i}\left(p^{i}-c\right) e^{i}\left(p^{i}, \tilde{w}^{i}\right)=F
$$

Letting $\lambda$ denote the Lagrange multiplier associated with constraint $(\mathrm{C} 1)$, the first-order conditions of the regulators problems are

$$
\begin{array}{cc}
v_{p}^{j}+v_{\tilde{w}}^{j} \tilde{e}^{j}+\lambda\left[e^{j}+\left(p^{j}-c\right)\left(e_{p}^{j}+e_{\tilde{w}}^{j} \tilde{e}^{j}\right)\right]=0 \quad \forall j \quad \text { (with respect to } p^{j} \text { ) and } \\
\left.-\sum_{i} v_{\tilde{w}}^{i}+\lambda\left[n-\sum_{i}\left(p^{i}-c\right) e_{\tilde{w}}^{i}\right]=0 \quad \text { (with respect to } t\right) .
\end{array}
$$

Applying Roy's identity $\left(-v_{p}^{j}=v_{\tilde{w}}^{j} e^{j}\right)$, equation (C2) becomes

$$
v_{\tilde{w}}^{j}\left(e^{j}-\tilde{e}^{j}\right)=\lambda\left[e^{j}+\left(p^{j}-c\right)\left(e_{p}^{j}+e_{\tilde{w}}^{j} \tilde{e}^{j}\right)\right] \quad \forall j
$$

Combining equations (C3) and (C4) yields

$$
\sum v_{w}^{i}=\frac{v_{\tilde{w}}^{j}\left(e^{j}-\tilde{e}^{j}\right)}{\left(e^{j}+\left(p^{j}-c\right)\left(e_{p}^{j}+e_{\tilde{w}}^{j} \tilde{e}^{j}\right)\right)}\left[n-\sum_{i}\left(p^{i}-c\right) e_{\tilde{w}}^{i}\right], \quad \forall j
$$

which can be rewritten as

$$
\left.L^{j} \equiv \frac{p^{j}-c}{p^{j}}=\frac{-1}{\left(\varepsilon_{p}^{j}+\frac{\tilde{e}^{j}}{e^{j}} p^{j} e_{\tilde{w}}^{j}\right.}\right)\left[1-\left(\frac{v_{\tilde{w}}^{j}}{\sum_{i} v_{\tilde{w}}^{i}}\right)\left(\frac{e^{j}-\tilde{e}^{j}}{e^{j}}\right)\left(n-\sum_{i}\left(p^{i}-c\right) e_{\tilde{w}}^{i}\right)\right], \quad \forall j
$$


This is equation (14) in the main paper. $L^{j}$ is the Lerner index of monopoly power with respect to household $j$, and $\varepsilon_{p}^{j}$ is household $j$ 's price elasticity of electricity demand: $\left(\partial e^{j} / \partial p^{j}\right)(p / e)<0$.

The Slutsky equation in this context says that compensated electricity demand, $h_{p}^{j}=e_{p}^{j}+e_{\tilde{w}}^{j} e^{j}<0$. Multiplying the right side of that that expression by $p^{j} / e^{j}$ yields the expression $\varepsilon_{p}^{j}+p^{j} e_{\tilde{w}}^{j}$. We know that is negative, from Slutsky, so multiplying the second term by $\tilde{e}^{j} / e^{j}<1$ to get the denominator in (C6) tells us that denominator is negative, since $\tilde{e}^{j}<e^{j}$ by assumption.

\section{Increasing Block Pricing}

To simplify, we assume that the access fee is $t=0$, and that an exogenous rule determines the number of households facing each of two price tiers: $n_{L}$ low-using customers face price $p_{L}$ for each kWh of electricity up to threshold quantity $q$, and $n_{H}$ high-using customers face price $p_{H}$ for each $\mathrm{kWh}$ above $q$. The budget constraint for the low types is

$$
x^{i}+p_{L}\left(e^{i}-\tilde{e}^{i}\right)=w^{i},
$$

and the budget constraint for the high types is

$$
x^{i}+p_{L} q+p_{H}\left(e^{i}-\tilde{e}^{i}-q\right)=w^{i} .
$$

As before, define $\tilde{w}_{L}^{i} \equiv w^{i}+p_{L} \tilde{e}$ and $\tilde{w}_{H}^{i} \equiv w^{i}+p_{H} \tilde{e}+\left(p_{H}-p_{L}\right) q$. The higher-users' problem is equivalent to paying a fixed fee $p_{L} q$ and per-kWh price $p_{H}\left(e^{i}-\tilde{e}^{i}-q\right)$.

The regulator chooses the two prices and the threshold, $\left\{p_{L}, p_{H}, q\right\}$, to maximize

$$
\sum_{i \in L} v^{i}\left(p_{L}, \tilde{w}_{L}^{i}\right)+\sum_{i \in H} v^{i}\left(p_{H}, \tilde{w}_{H}^{i}\right)
$$

subject to the zero profit constraint that 


$$
\left(p_{L}-c\right)\left[n_{H} q+\sum_{i \in L} e^{i}\left(p_{L}, \tilde{w}_{L}^{i}\right)\right]+\left(p_{H}-c\right)\left[\sum_{i \in H} e^{i}\left(p_{H}, \tilde{w}_{H}^{i}\right)\right]=F
$$

Letting $\lambda$ be the constraint on (D4), and using Roy's identity to rewrite $v_{p}^{i}$ as $-e^{i} v_{\tilde{w}}^{i}$, the three first-order conditions are

$$
\begin{aligned}
& \left.-\sum_{i \in H} v_{\tilde{w}}^{i}\left(e^{i}-\tilde{e}^{i}-q\right)+\lambda \sum_{i \in H}\left(e^{i}+\left(p_{H}-c\right)\left(e_{p}^{i}+e_{\tilde{w}}^{i}\left(\tilde{e}^{i}-q\right)\right)\right)=0 \quad \text { (with respect to } p_{H}\right), \\
& -\sum_{i \in L} v_{\tilde{w}}^{i}\left(e^{i}-\tilde{e}^{i}\right)-q \sum_{i \in H} v_{\tilde{w}}^{i}+\lambda\left[n_{H} q+\sum_{i \in L}\left(e^{i}+\left(p_{L}-c\right)\left(e_{p}^{i}+e_{\tilde{w}}^{i} \tilde{e}^{i}\right)\right)-\left(p_{H}-c\right) q \sum_{i \in H} e_{\tilde{w}}^{i}\right]=0
\end{aligned}
$$

(with respect to $p_{L}$ ), and

$$
\left.\left(p_{H}-p_{L}\right) \sum_{i \in H} v_{\tilde{w}}^{i}+\lambda\left[n_{H}\left(p_{L}-c\right)+\left(p_{H}-c\right)\left(p_{H}-p_{L}\right) \sum_{i \in H} e_{\tilde{w}}^{i}\right]=0 \quad \text { (with respect to } q\right) \text {. }
$$

Consider equation (D7). The first term is positive, so the bracketed term that multiplies $\lambda$ must be negative. So either $p_{L}<c$ or $\left(p_{H}-c\right)\left(p_{H}-p_{L}\right)<0$. Since $p_{H}>p_{L}$ by assumption, and since equation (D4) must hold, it must be the case that that $p_{H}>c>p_{L}$. That is intuitive. Customers using less than $q$ will pay below marginal cost, $p_{L}<c$, and customers using more than $q$ will pay above marginal cost $p_{H}>c$ for all electricity above $q$.

Combining equations (D5) and (D7) yields

$$
\begin{aligned}
& \frac{-\left(p_{L}-c\right)}{p_{L}}=\left(\frac{p_{H}-p_{L}}{p_{L}}\right) \times \\
& {\left[\frac{\left(p_{H}-c\right) \sum_{i \in H} e_{\tilde{w}}^{i} \sum_{i \in H} v_{\tilde{w}}^{i}\left(e^{i}-\tilde{e}^{i}-q\right)+\sum_{i \in H} v_{\tilde{w}}^{i}\left(\sum_{i \in H} e_{\tilde{w}}^{i}+\left(p_{H}-c\right) \sum_{i \in H}\left(e_{p}^{i}+e_{\tilde{w}}^{i}\left(\tilde{e}^{i}+q\right)\right)\right)}{n_{H} \sum_{i \in H} v_{\tilde{w}}^{i}\left(e^{i}-\tilde{e}^{i}-q\right)}\right]=0 .}
\end{aligned}
$$

Intuitively, the rate at which low-demand customers are subsidized is proportional to the size of the gap between the high and low prices. Lowering $p_{L}$ requires raising $p_{H}$.

Combining equations (D5) and (D6) yields 


$$
\frac{\sum_{i \in H} v_{\tilde{w}}^{i}\left(e^{i}-\tilde{e}^{i}-q\right)}{\sum_{i \in L} v_{\tilde{w}}^{i}\left(e^{i}-\tilde{e}^{i}\right)+q \sum_{i \in H} v_{\tilde{w}}^{i}}=\frac{E^{H}+\left(p_{H}-c\right) \sum_{i \in H}\left(e_{p}^{i}+e_{\tilde{w}}^{i}\left(\tilde{e}^{i}+q\right)\right)}{E^{L}+\left(p_{L}-c\right) \sum_{i \in L}\left(e_{p}^{i}+e_{\tilde{w}}^{i} \tilde{e}^{i}\right)+n_{H} q-\left(p_{H}-c\right) q \sum_{i \in H} e_{\tilde{w}}^{i}},
$$

where $E^{H}=\sum_{i \in H} e^{i}$ and $E^{L}=\sum_{i \in L} e^{i}$. The left side of (D9) is the rate at which $p_{L}$ can be lowered and $p_{H}$ can be raised, holding total utility constant. It is the marginal social rate of substitution between the high and low electricity prices. The right side of (D9) is the rate at which $p_{L}$ can be lowered and $p_{H}$ raised, holding total revenue constant. It is the marginal social rate of transformation between high and low electricity prices. 


\section{E. Appendix Tables}

\section{Appendix Table E1: Winter Electric Gini and Local Population Characteristics}

\begin{tabular}{|c|c|c|c|c|c|c|}
\hline \multirow[b]{2}{*}{ Variables } & \multicolumn{6}{|c|}{ Regressions } \\
\hline & $(1)$ & $(2)$ & (3) & (4) & $(5)$ & $(6)$ \\
\hline Household income & 0.119* & & & 0.094* & 0.069* & 0.007 \\
\hline Gini 2015 & $(0.034)$ & & & $(0.031)$ & $(0.031)$ & $(0.032)$ \\
\hline $\begin{array}{l}\text { Share below } \\
\text { poverty line }\end{array}$ & & $\begin{array}{l}-0.012 \\
(0.014)\end{array}$ & & & & \\
\hline Average income & & & $0.005^{*}$ & 0.001 & -0.000 & -0.001 \\
\hline$(\$ 10,000)$ & & & $(0.001)$ & $(0.001)$ & $(0.001)$ & $(0.001)$ \\
\hline State tax/transfer & & & & $-0.508^{*}$ & $-0.470^{*}$ & $-0.773^{*}$ \\
\hline effect on Gini & & & & $(0.201)$ & $(0.200)$ & $(0.205)$ \\
\hline Democratic vote & & & & $0.039 *$ & $0.035^{*}$ & $0.032 *$ \\
\hline share & & & & $(0.008)$ & $(0.008)$ & $(0.008)$ \\
\hline Fraction of sales & & & & $-0.021 *$ & $-0.022 *$ & $-0.020^{*}$ \\
\hline residential & & & & $(0.005)$ & $(0.005)$ & $(0.005)$ \\
\hline Res. customers & & & & 0.001 & -0.002 & -0.003 \\
\hline (mill.) & & & & $(0.004)$ & $(0.004)$ & $(0.004)$ \\
\hline Average electricity & & & & $0.178 *$ & $0.147^{*}$ & $0.095^{*}$ \\
\hline price $(\$ / k W h)$ & & & & $(0.031)$ & $(0.032)$ & $(0.035)$ \\
\hline Investor-owned & & & & 0.001 & -0.001 & -0.000 \\
\hline utility & & & & $(0.004)$ & $(0.004)$ & $(0.004)$ \\
\hline Cooperative utility & & & & $-0.026^{*}$ & $-0.025^{*}$ & $-0.025^{*}$ \\
\hline & & & & $(0.002)$ & $(0.002)$ & $(0.002)$ \\
\hline Has a means- & & & & & $0.008^{*}$ & 0.006 \\
\hline tested rate & & & & & $(0.003)$ & $(0.003)$ \\
\hline Noncompliance & & & & & $0.001^{*}$ & $0.001 *$ \\
\hline with NAAQS & & & & & $(0.000)$ & $(0.000)$ \\
\hline Correlation & & & & & 0.015 & 0.005 \\
\hline (income, elect) & & & & & $(0.011)$ & $(0.012)$ \\
\hline Share electricity & & & & & & $0.037^{*}$ \\
\hline from gas & & & & & & $(0.005)$ \\
\hline Share electricity & & & & & & $0.011 *$ \\
\hline from nuclear & & & & & & $(0.006)$ \\
\hline Share electricity & & & & & & 0.007 \\
\hline from hydro & & & & & & $(0.006)$ \\
\hline Share electricity & & & & & & 0.041 \\
\hline from petroleum & & & & & & $(0.022)$ \\
\hline Constant & $0.242 *$ & $0.297^{*}$ & $0.264^{*}$ & 0.199* & $0.219 *$ & $0.228^{*}$ \\
\hline & $(0.015)$ & $(0.003)$ & $(0.004)$ & $(0.021)$ & $(0.022)$ & $(0.022)$ \\
\hline$N$ & 1,305 & 1,305 & 1,305 & 1,305 & 1,305 & 1,305 \\
\hline R2 & 0.01 & 0.00 & 0.04 & 0.30 & 0.32 & 0.34 \\
\hline
\end{tabular}

Notes: Asterisks $\left({ }^{*}\right)$ denote statistically significance at $5 \%$. 


\section{F. Appendix Figures}

Appendix Figure F1: Gini Coefficients for 2015 Household Incomes, by US County.

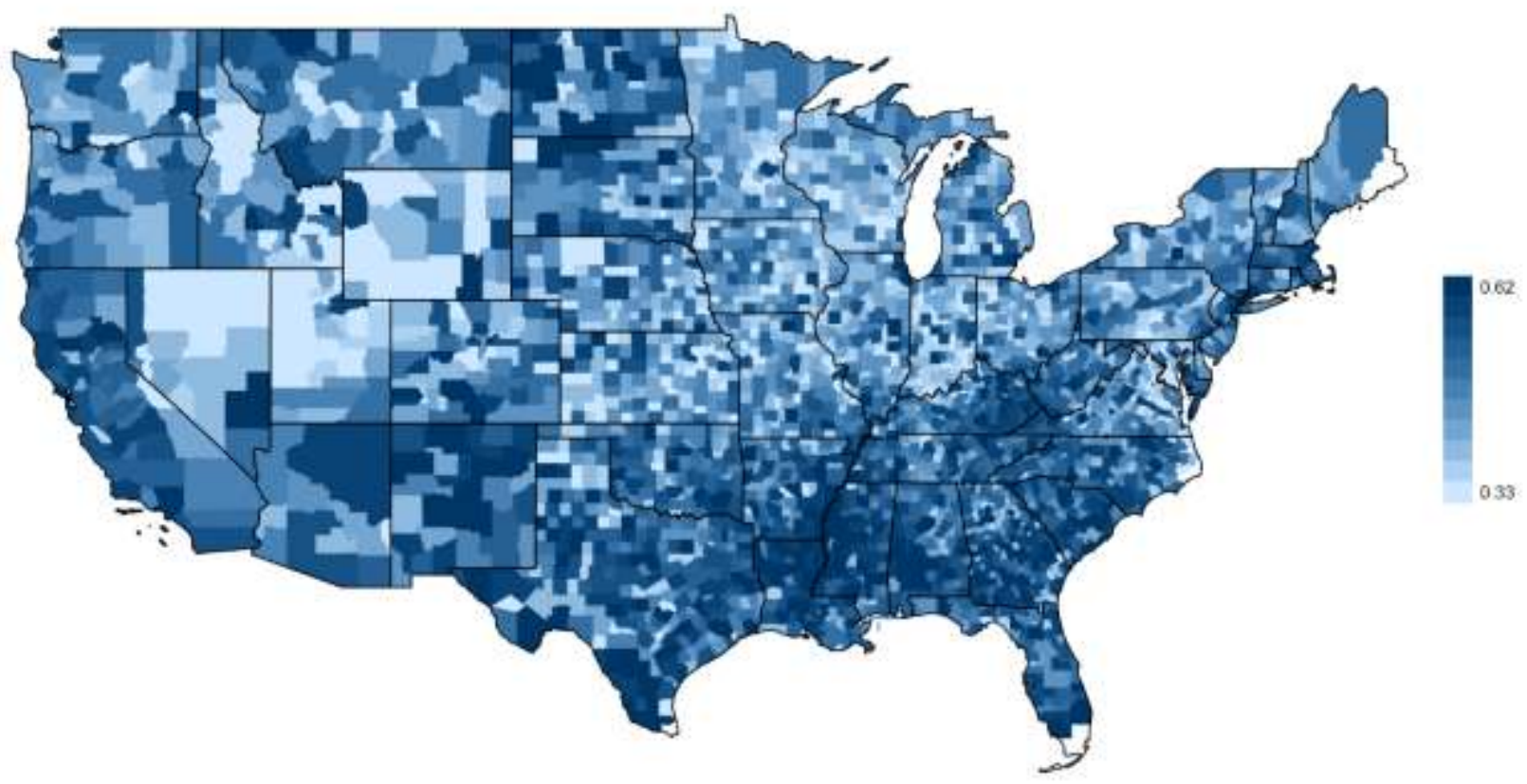

Source: American Community Survey, 2015.

Appendix Figure F2: Electric Ginis, by Utility Service Area

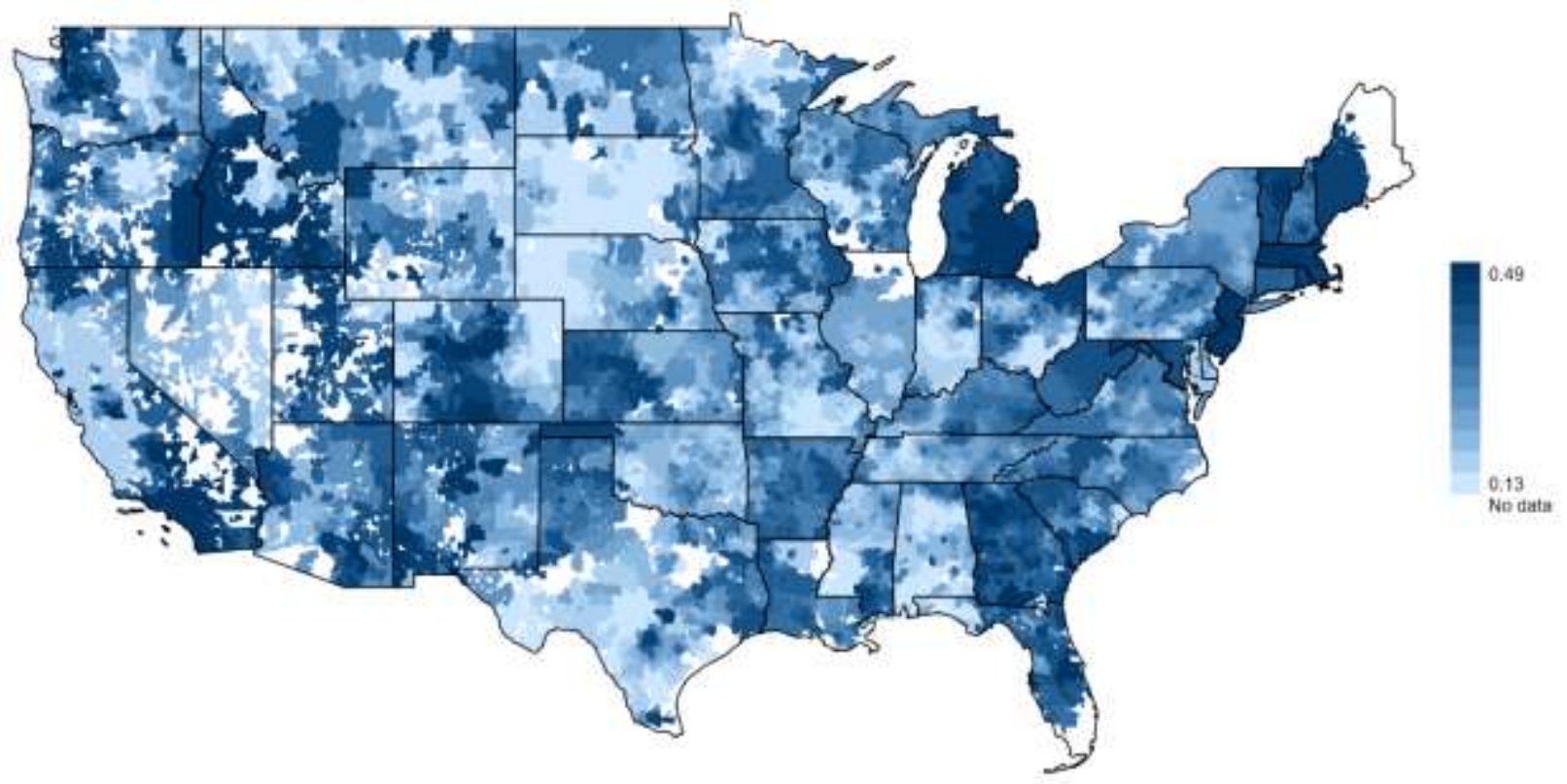

Source: Authors' calculations from Utility Rate Database, summer electricity prices. 
Appendix Figure F3: Electricity Lorenz Curves for Example Utilities

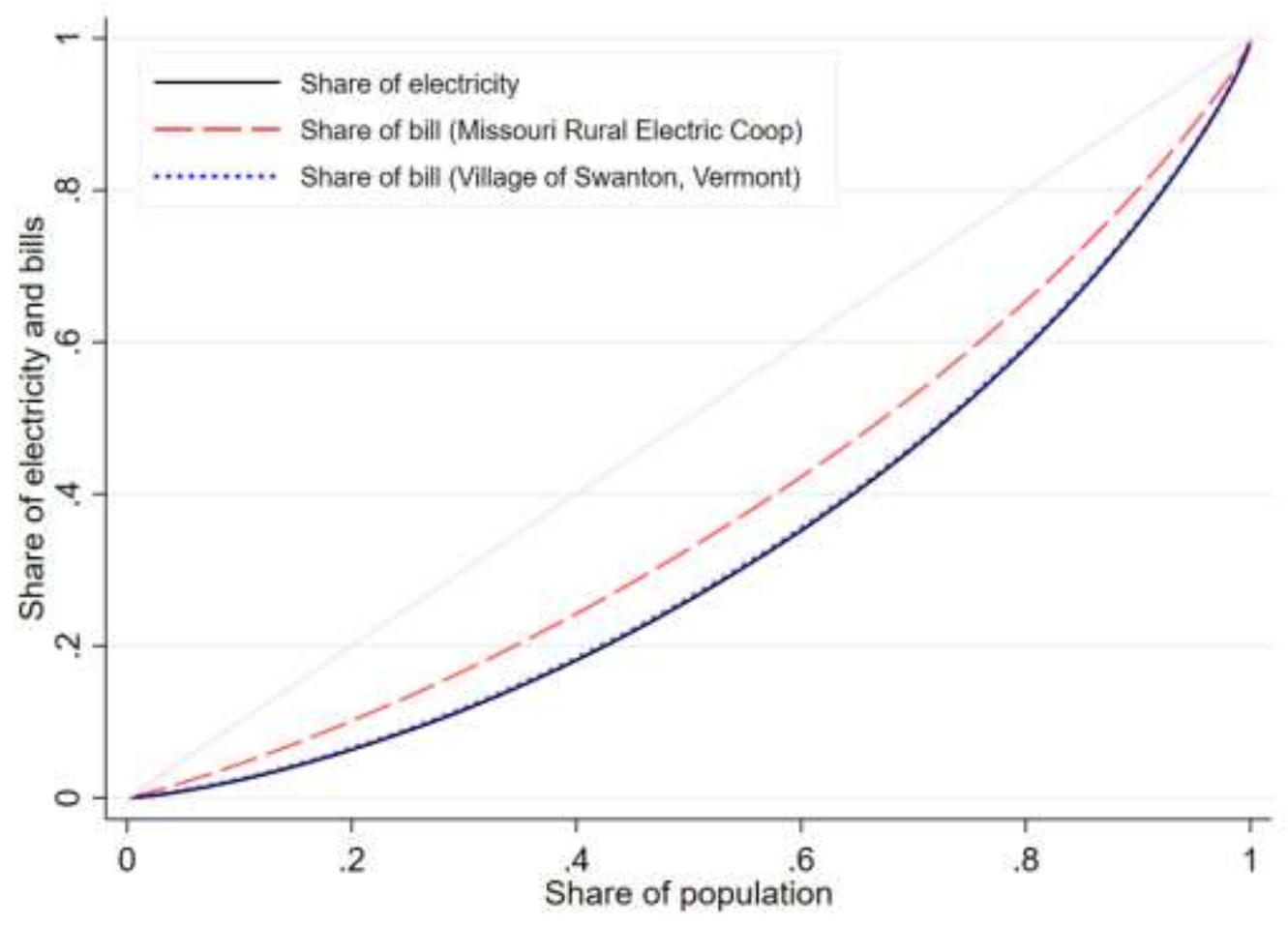

Appendix Figure F4: Distributions of PG\&E August Electricity Use by Household Income

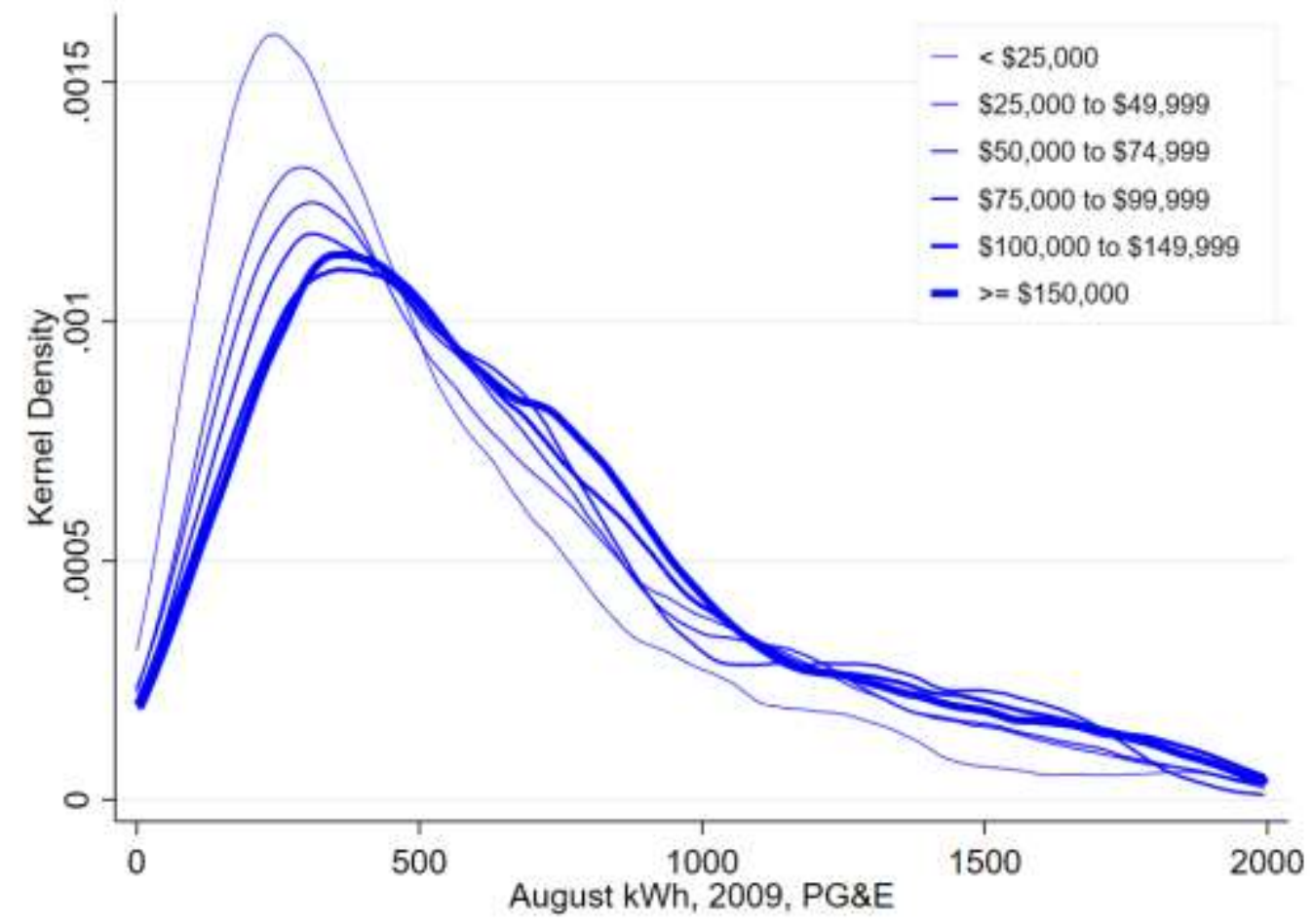

Source: Authors' calculations from 2009 Residential Appliance Saturation Survey. 
Appendix Figure F5: Higher-Income Households Spend Less Time at Home

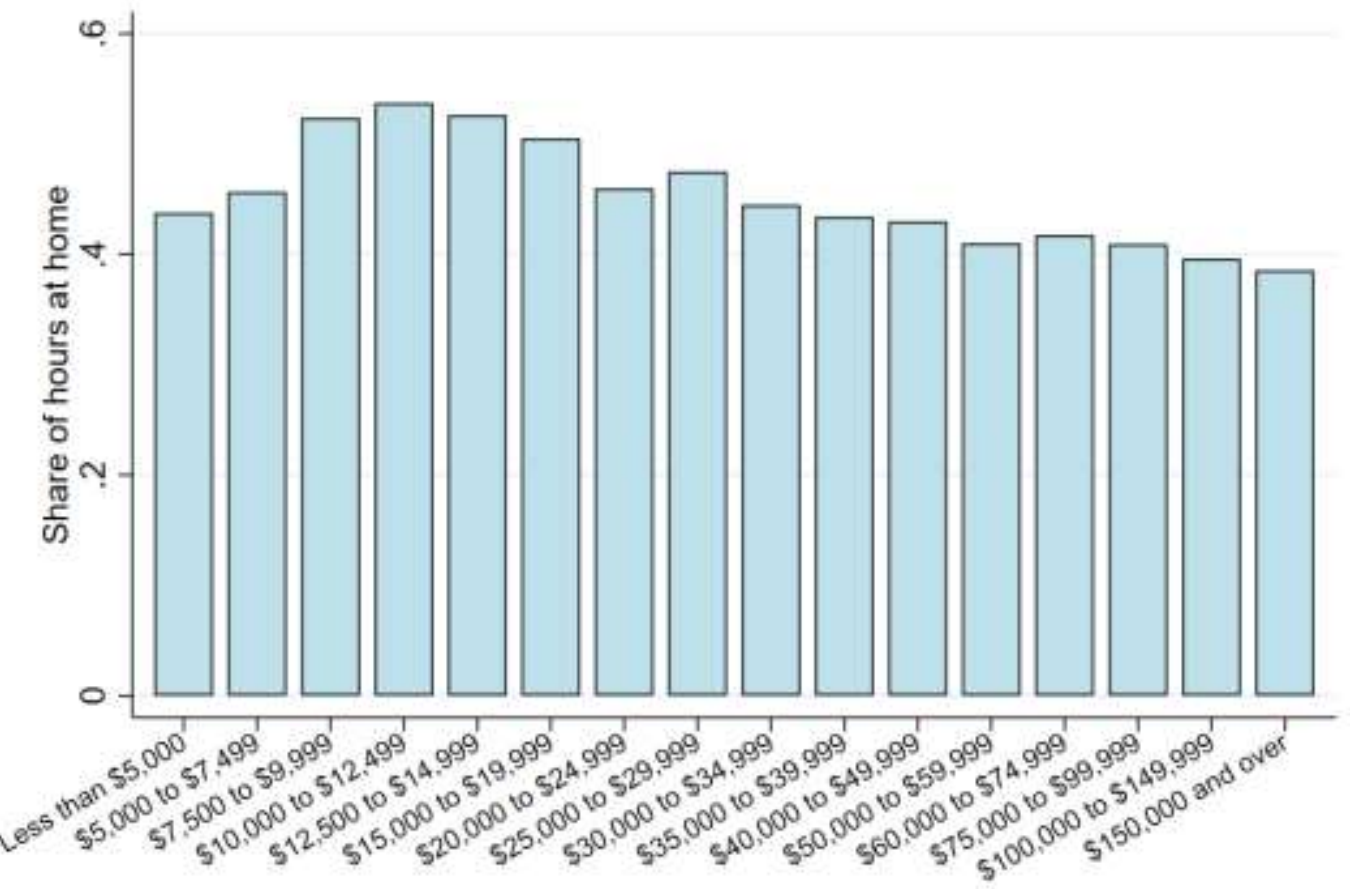

Family income

Source: Authors' calculations from 2017 American Time Use Survey.

Appendix Figure F6: Correlation between Income and Electricity Use

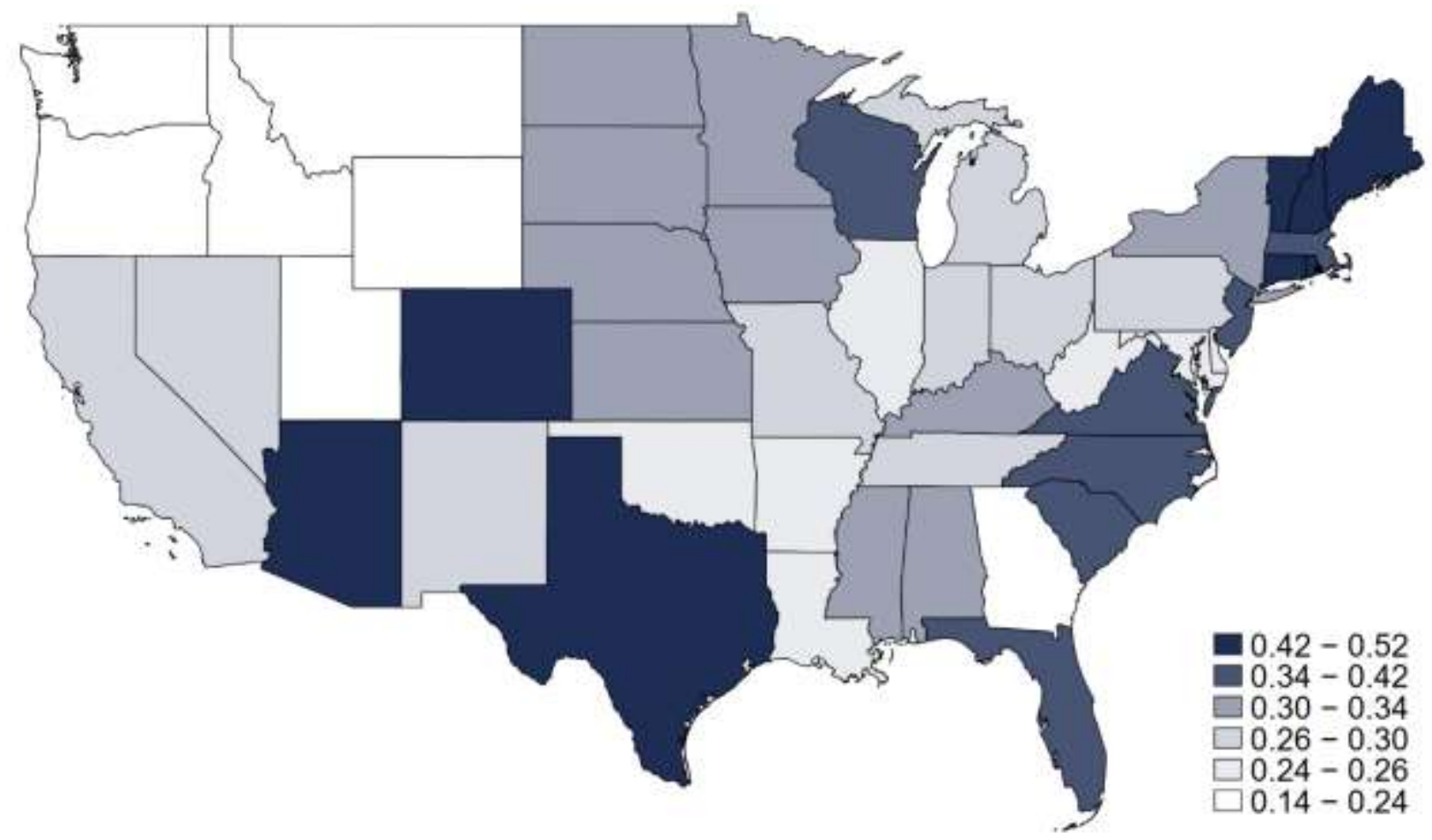

Source: Authors' calculations from 2009 Residential Energy Consumption Survey. 